\title{
Differential Projections of the Infralimbic and Prelimbic Cortex in the Rat
}

\author{
ROBERT P. VERTES* \\ Center for Complex Systems and Brain Sciences, Florida Atlantic University, Boca Raton, Florida 33431
}

KEY WORDS agranular insular cortex; claustrum; nucleus accumbens; nucleus reuniens; prelimbic circuit; visceromotor activity; working memory

\begin{abstract}
The medial prefrontal cortex has been associated with diverse functions including attentional processes, visceromotor activity, decision-making, goal-directed behavior, and working memory. The present report compares and contrasts projections from the infralimbic (IL) and prelimbic (PL) cortices in the rat by using the anterograde anatomical tracer, Phaseolus vulgaris-leucoagglutinin. With the exception of common projections to parts of the orbitomedial prefrontal cortex, olfactory forebrain, and midline thalamus, PL and IL distribute very differently throughout the brain. Main projection sites of IL are: 1) the lateral septum, bed nucleus of stria terminalis, medial and lateral preoptic nuclei, substantia innominata, and endopiriform nuclei of the basal forebrain; 2) the medial, basomedial, central, and cortical nuclei of amygdala; 3) the dorsomedial, lateral, perifornical, posterior, and supramammillary nuclei of hypothalamus; and 4) the parabrachial and solitary nuclei of the brainstem. By contrast, PL projects at best sparingly to each of these structures. Main projection sites of PL are: the agranular insular cortex, claustrum, nucleus accumbens, olfactory tubercle, the paraventricular, mediodorsal, and reuniens nuclei of thalamus, the capsular part of the central nucleus and the basolateral nucleus of amygdala, and the dorsal and median raphe nuclei of the brainstem. As discussed herein, the pattern of IL projections is consistent with a role for IL in the control of visceral/autonomic activity homologous to the orbitomedial prefrontal cortex of primates, whereas those of PL are consistent with a role for PL in limbic-cognitive functions homologous to the dorsolateral prefrontal cortex of primates. Synapse 51:32-58, 2004. ๑ 2003 Wiley-Liss, Inc.
\end{abstract}

\section{INTRODUCTION}

The medial prefrontal cortex (mPFC) in the rat consists of four main subdivisions which, from dorsal to ventral, are the medial agranular (AGm) (or medial precentral), the anterior cingulate (AC) (dorsal and ventral divisions), the prelimbic (PL), and the infralimbic (IL) cortices (Berendse and Groenewegen, 1991; Ray and Price, 1992; Price, 1995; Swanson, 1998; Ongur and Price, 2000).

The $\mathrm{mPFC}$ has been associated with diverse functions including oculomotor control (frontal eye fields), attentional processes, visceromotor activity, decisionmaking, goal-directed behavior, and working memory (Goldman-Rakic, 1987, 1994; Fuster, 1989; Neafsey et al., 1986a; Kolb, 1990; Neafsey, 1990; Petrides, 1995, 1998). The various subdivisions of $\mathrm{mPFC}$ appear to serve separate and distinct functions. For instance, dorsal regions of $\mathrm{mPFC}$ (AGm and $\mathrm{AC}$ ) have been implicated in various motor behaviors, while ventral regions of $\mathrm{mPFC}$ (PL and IL) have been associated with diverse emotional, cognitive, and mnemonic processes.
Early reports in rats showed that stimulation of AGm/AC generated eye movements (Hall and Lindholm, 1974; Donoghue and Wise, 1982), which together with the demonstration that $\mathrm{AGm} / \mathrm{AC}$ projects to oculomotor sites (Beckstead, 1979; Hardy and Leichnetz, 1981; Neafsey et al., 1986a; Leichnetz and GonzaloRuiz, 1987; Leichnetz et al., 1987; Reep et al., 1987; Stuesse and Newman, 1990), led to the proposal that $\mathrm{AGm} / \mathrm{AC}$ of rats was equivalent to the frontal eye fields (FEF) of primates (Leonard, 1969; Leichnetz and Gonzalo-Ruiz, 1987; Reep et al., 1984, 1987; Guandalini, 1998). Subsequent reports confirmed AGm involvement in eye movement control, and further

Contract grant sponsor: NIMH; Contract grant numbers: MH63519, MH01476.

*Correspondence to: Dr. Robert P. Vertes, Center for Complex Systems and Brain Sciences, Florida Atlantic University, Boca Raton, FL 33431.

E-mail: Vertes@ccs.fau.edu

Received 8 May 2003; Accepted 31 July 2003

DOI 10.1002/syn.10279 
showed that AGm stimulation produced other types of movements including those of the vibrissa, head, and hindlimbs (Neafsey and Sievert, 1982; Sanderson et al., 1984; Sinnamon and Galer, 1984; Gioanni and Lamarche, 1985; Neafsey et al., 1986a). Accordingly, it has been variously proposed that the $\mathrm{AGm} / \mathrm{AC}$ of rats is homologous to the FEF, supplementary motor, and premotor cortices of primates (Neafsey et al., 1986a; Passingham et al., 1988; Reep et al., 1987, 1990).

In contrast to motor-associated properties of the dorsal mPFC, the ventral mPFC (IL and PL) has been anatomically and functionally linked with the limbic system. For instance, the ventral mPFC (or IL) has been shown to profoundly influence visceral/autonomic activity. IL stimulation produces changes in respiration, gastrointestinal motility, heart rate, and blood pressure (Terreberry and Neafsey, 1983; Burns and Wyss, 1985; Hurley-Gius and Neafsey, 1986; Verberne et al., 1987; Hardy and Holmes, 1988). IL has been viewed as a visceromotor center (Hurley-Gius and Neafsey, 1986; Neafsey, 1990), homologous to the orbitomedial prefrontal cortex of primates (Barbas, 1995, 2000; Groenewegen and Uylings, 2000).

The ventral mPFC (primarily PL) has also been implicated in cognitive processes. Ventral mPFC lesions

Abbreviations

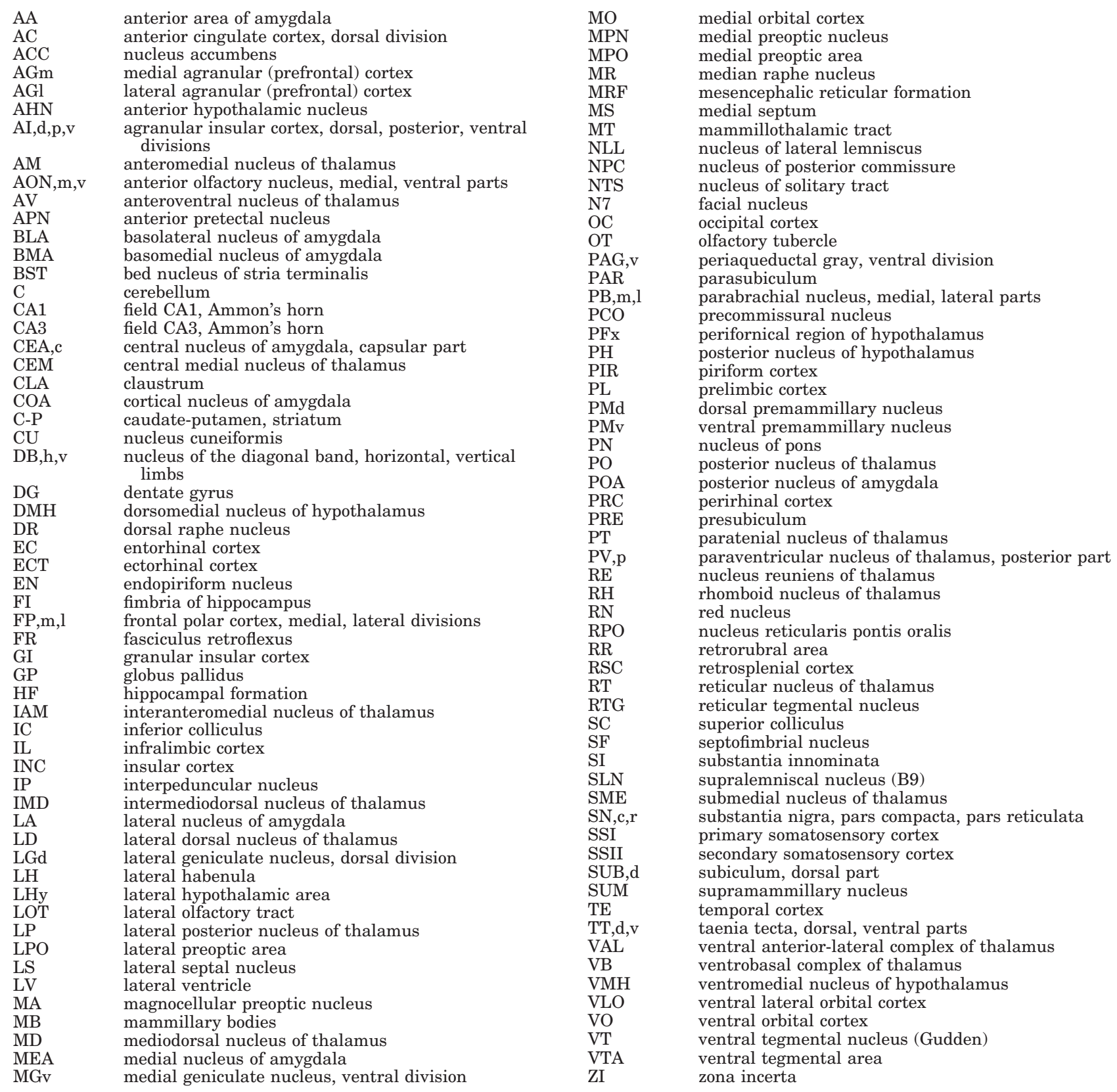


(or PL lesions) have been shown to produce pronounced deficits in delayed response tasks (Brito and Brito, 1990; Seamans et al., 1995; Delatour and Gisquet-Verrier, 1996, 1999, 2000; Floresco et al., 1997; Ragozzino et al., 1998), similar to those seen with lesions of the dorsolateral PFC of primates (Kolb, 1984; GoldmanRakic, 1987, 1994; Groenewegen and Uylings, 2000).

A view appears to be emerging that IL primarily serves a role in visceromotor functions and PL in cognitive processes. Despite apparent functional differences, IL and PL are often (or generally) treated as a single region (i.e., the ventral $\mathrm{mPFC}$ ), with reportedly minor differences in their efferent projections. For instance, following an analysis of IL, PL, and anterior cingulate projections in rabbits, Buchanan et al. ( 1994) concluded that: "there were many similarities between the projections from the three cytoarchitectonic areas." In like manner, Takagishi and Chiba (1991) examined IL projections in the rat, compared their findings to an earlier description of PL projections in rats (Sesack et al., 1989), and reported that 26 of 27 sites receive common projections from IL and PL (see their fig. 10, p. 35). Finally, Price and co-workers (Floyd et al., 2000, 2001) recently demonstrated significantly overlapping IL and PL projections to the periaqueductal gray (PAG) and hypothalamus in rats, stating, for instance (Floyd et al., 2001) that: "Projections from rostral PL/IL targeted the rostrocaudal extent of the lateral hypothalamus"; and "Projections arising from the caudal PL/IL terminated within the dorsal hypothalamus."

In the present report, we examine, compare, and contrast projections from the IL and PL cortices in the rat and show, with few exceptions, that IL and PL distribute very differently throughout the brain. These differential projections undoubtedly reflect distinct functions for IL and PL.

\section{MATERIALS AND METHODS}

Single injections of PHA-L were made into the IL or PL of 26 male Sprague-Dawley (Charles River, Wilmington, MA) rats weighing $275-325 \mathrm{~g}$. These experiments were approved by the Florida Atlantic University Institutional Animal Care and Use Committee and conform to all federal regulations and the National Institutes of Health Guidelines for the Care and Use of Laboratory Animals.

Powdered lectin from Phaseolus vulgaris-leucoagglutinin was reconstituted to $2.5 \%$ in $0.05 \mathrm{M}$ sodium phosphate buffer, $\mathrm{pH}$ 7.4. The PHA-L solution was iontophoretically deposited in the brains of anesthetized rats by means of a glass micropipette with an outside tip diameter of 40-60 $\mu \mathrm{m}$. Positive direct current (5-10 $\mu \mathrm{A})$ was applied through a Grass stimulator (Model 88) coupled with a high-voltage stimulator (FHC, Bowdoinham, $\mathrm{ME}$ ) at $2 \mathrm{sec}$ "on" / $2 \mathrm{sec}$ "off" intervals for 30-40 min. After a survival time of 7-10 days, animals were deeply anesthetized with sodium pentobarbital and perfused transcardially with a buffered saline wash $(\mathrm{pH} 7.4,300$ $\mathrm{ml} /$ animal) followed by fixative (2.5\% paraformaldehyde, $0.05-0.1 \%$ glutaraldehyde in $0.05 \mathrm{M}$ phosphate buffer, $\mathrm{pH} 7.4)(300-500 \mathrm{ml} /$ animal), and then by $10 \%$ sucrose in the same phosphate buffer $(150 \mathrm{ml} / \mathrm{animal})$. The brains were removed and stored overnight at $4^{\circ} \mathrm{C}$ in $20 \%$ sucrose in the same phosphate buffer. On the following day, 40 or $50 \mu \mathrm{m}$ frozen sections were collected in phosphate-buffered saline (PBS, $0.9 \%$ sodium chloride in $0.01 \mathrm{M}$ sodium phosphate buffer, $\mathrm{pH}$ 7.4) and incubated for $1 \mathrm{~h}$ in diluent (10\% normal rabbit serum (Colorado Serum, Denver, CO) and 1\% Triton X-100 (Sigma Chemicals, St. Louis, MO), in PBS). Sections were then incubated overnight (14-17 h) at $4^{\circ} \mathrm{C}$ in primary antiserum directed against PHA-L (biotinylated goat anti-PHA-L, Vector Laboratories, Burlingame, CA) at a dilution of 1:500 in diluent. The next day, sections were washed 5 times for 5 min each $(5 \times 5$ $\mathrm{min}$ ) in PBS, and then incubated in the second antiserum (rabbit antisheep IgG, Vector Labs) at a dilution of 1:500 in diluent for $2 \mathrm{~h}$. Sections were rinsed again $(5 \times 5$ min) and incubated with peroxidase-antiperoxidase (goat origin, Sternberger Monoclonals, Baltimore, MD) at a dilution of 1:250 for $2 \mathrm{~h}$. The last two incubations were repeated (double-bridge procedure) with $5 \times 5$ min rinses following each incubation for $1 \mathrm{~h}$ each. After $5 \times 5 \mathrm{~min}$ rinses the sections were incubated in $0.05 \% 3,3^{\prime}$ diaminobenzidine (DAB) in PBS for $10 \mathrm{~min}$, followed by a second, 5-min DAB (same concentration) incubation to which $0.018 \%$ $\mathrm{H}_{2} \mathrm{O}_{2}$ had been added. Sections were then rinsed again in PBS ( $3 \times 1 \mathrm{~min})$ and mounted onto chromealum gelatin-coated slides. An adjacent series of sections was stained with cresyl violet for anatomical reference.

Sections were examined using light and darkfield optics. PHA-L-labeled cells (at injection sites) and fibers were plotted onto maps constructed from adjacent Nissl-stained sections. The main criteria used to distinguish labeled terminals from fibers of passage were: 1) the presence or essential absence of axon/terminal specializations; and 2) the degree of axonal branching. Terminal sites were typically characterized by a dense array of highly branched axons containing numerous specializations (varicosities, terminal boutons), whereas passing fibers exhibited minimal branching and contained few specializations. The lightfield photomicrographs of the injection sites were taken with a Nikon DXM1200 camera mounted on a Nikon Eclipse E600 microscope and enhanced (contrast and brightness) using Adobe PhotoShop 7.0 (Mountain View, CA), while the darkfield photomicrographs of labeled fibers were taken with a Nikon FX-35A $35 \mathrm{~mm}$ camera.

\section{RESULTS}

The patterns of distribution of labeled fibers throughout the brain with injections in the infralimbic (IL) and prelimbic (PL) cortices are described. Two cases are depicted and described in detail: one with an 
injection in IL (case 701) (Fig. 1A) and the other with an injection in PL (case 668) (Fig. 1B,C). The patterns of labeling obtained with the schematically illustrated cases (see below) are representative of patterns found with nonillustrated cases.

\section{Infralimbic cortex: case 701}

Figure 2 schematically depicts patterns of labeling throughout the brain following a PHA-L injection in the infralimbic cortex (Fig. 2C). PHA-L-filled cells were primarily localized to layer 6 of IL, with some extension to layer 5, mainly ventrally in layer 5 (Fig. 1A).

Labeled fibers coursed forward from the site of injection to distribute to frontal polar regions of cortex and olfactory structures (Fig. 2A). Labeled fibers spread dorsoventrally throughout the medial wall of mPFC terminating in the medial frontal polar cortex (FPm), the rostral prelimbic cortex, and the medial orbital cortex (MO). Significant numbers also extended laterally from MO to distribute to the ventrolateral (VLO) and lateral (LO) orbital cortices. Labeling was heaviest in ventral FPm and PL and largely restricted to layers 1 and $5 / 6$ of these regions. The primary olfactory targets were the anterior olfactory nucleus (AONm) and the dorsally adjacent dorsal tania tecta (TTd) (layers 2-4), with some extension to the ventral tania tecta (TTv) (Fig. 2A). Labeling was considerably stronger ipsilaterally (left side) than contralaterally.

Further caudally (Fig. 2B), labeled fibers continued to occupy most of the medial wall of $\mathrm{mPFC}$, mainly confined to the anterior cingulate (AC), PL, and medial orbital cortices. Although labeling spread to all layers of cortex, it was most densely concentrated in layers 1 and 5/6 of mPFC. A few labeled fibers were observed laterally in VLO. The AONm and TTV were moderately labeled.

Like rostrally (Fig. 2A,B), the principal destination of labeled fibers at the site of injection (Fig. 2C) was regions of the cortex and olfactory structures. The $\mathrm{AC}, \mathrm{PL}$, and IL were heavily labeled; the dorsal agranular insular cortex (AId), rostral endopiriform nucleus (EN), and anterior ventral olfactory nucleus $(\mathrm{AONv})$ were moderately labeled. As depicted (Fig. $2 \mathrm{C}$ ), there was a notable absence of labeling in nucleus accumbens (ACC).

Labeled fibers descended from the site of injection primarily through dorsomedial aspects of cortex and through the medial one-third of the striatum (C-P) to distribute strongly to AC, IL, TTd, and anterolateral regions of the septum, and less heavily to the olfactory tubercle $(\mathrm{OT})$, ventral agranular insular cortex (AIv), and EN (bilaterally) (Fig. 2D,E). The ACC was lightly labeled ipsilaterally. Further caudally, labeled fibers, grouped in small bundles, descended through the medial striatum (Fig. 2E,F), distributing en route to dorsal and ventral parts of medial C-P, and beyond the striatum to the lateral septum (LS),
OT, EN, the posterior agranular insular cortex (AIp), and the horizontal limb of diagonal band nucleus (DBh). Labeled axons appeared to mainly traverse the medial ACC bound for caudal regions of the basal forebrain (Fig. 2E,F).

At the mid-septum (Fig. 2G), labeled fibers spread widely over the basal forebrain, strongly targeting anterior regions of the bed nucleus of stria terminalis (BST), the substantia innominata (SI), DBh, and EN, and, moderately, the medial C-P, AC, and LS. At the caudal septum (Fig. 2H,I), labeling was mainly confined to structures of the medial basal forebrain and anterior hypothalamus. Major sites of termination were BST (all divisions), EN, lateral aspects of the medial preoptic area (MPO), and the lateral preoptic area (LPO), with extensions caudally to the lateral hypothalamus (LHy) (Fig. 2I). This pattern of labeling is depicted in the photomontage of Figure 3. Labeled fibers surrounded but did not appear to terminate in the magnocellular preoptic nucleus (MA), while some distributed to the medial preoptic nucleus (MPN) (Fig. $2 \mathrm{H})$. Only scattered labeling was observed in the cortex, essentially restricted to AC.

The main route of descent of labeled fibers through the diencephalon was the medial forebrain bundle (MFB). A major contingent of labeled axons coursed dorsomedially from the MFB into the thalamus to terminate massively in the paratenial nucleus (PT), medial and central divisions of the mediodorsal nucleus (MDm and $\mathrm{MDc}$ ) and nucleus reuniens (RE) (Fig. 2J,K). Others continuing to descend with the MFB distributed terminally in transit to lateral (LHy) and perifornical $(\mathrm{PFx})$ regions of the hypothalamus. The anterior amygdala was fairly uniformly labeled (Fig $2 \mathrm{~J}-\mathrm{L}$ ); labeling was densest in the medial, cortical (anterior and posterolateral parts), and central (medial and capsular regions) nuclei (Fig. 4). The caudal pole of BST, zona incerta (ZI), EN, and the rhomboid $(\mathrm{RH})$ and central medial (CEM) nuclei of thalamus were moderately labeled (Fig. 2J,K).

Further caudally in the diencephalon (Fig. 2L,M), labeling was largely confined to the midline thalamus, hypothalamus, and amygdala; that is, 1) to the MD complex, dorsally, and RE, ventrally, of the thalamus; 2) to the perifornical region, LHy, and dorsomedial nuclei of the hypothalamus; and 3) to the medial, basomedial, and central (medial and capsular divisions) nuclei of the amygdala.

Labeling thinned considerably at caudal levels of the diencephalon (Fig. 2N,O). Moderately dense numbers of labeled fibers, however, were present in the posterior paraventricular ( $\mathrm{PVp})$, intermediodorsal (IMD), and medial aspects of the parafascicular (PF) nuclei of thalamus, as well as in the lateral, posterior, and supramammillary (SUM) nuclei of the hypothalamus. Caudal regions of the amygdala were sparsely labeled. Figure 5 shows significant labeling 
A

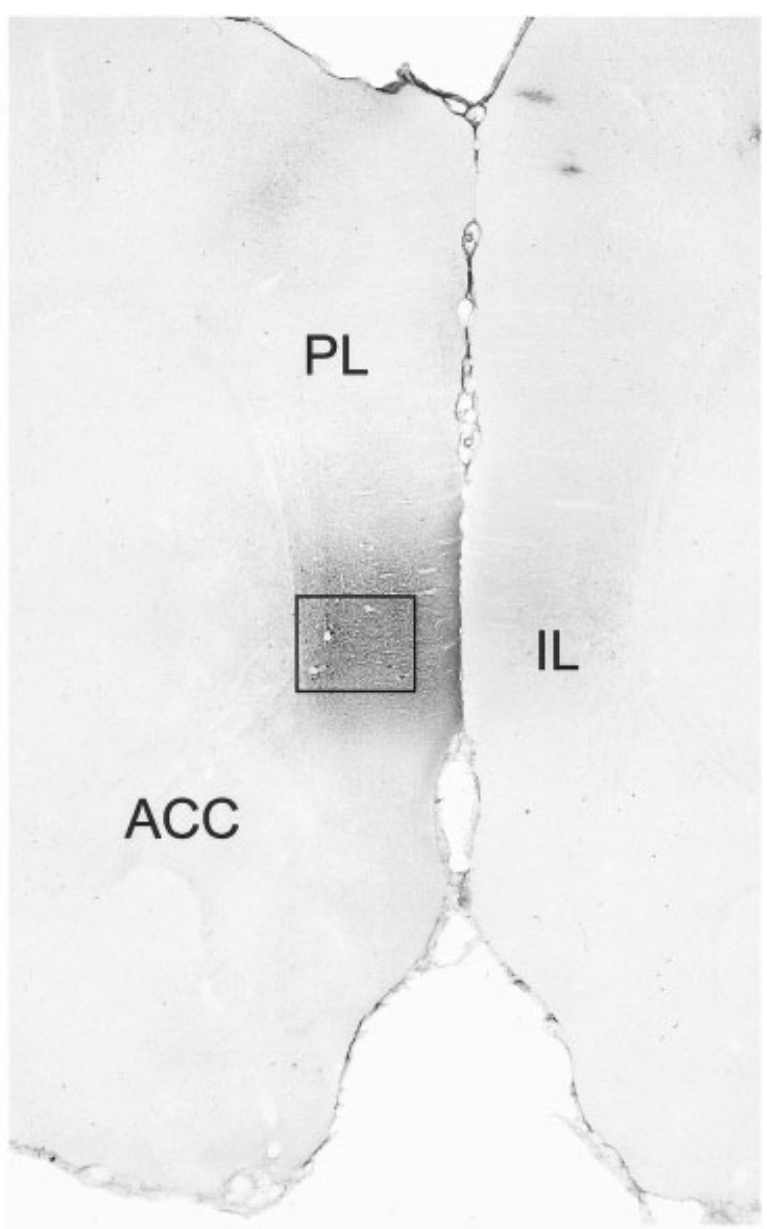

B

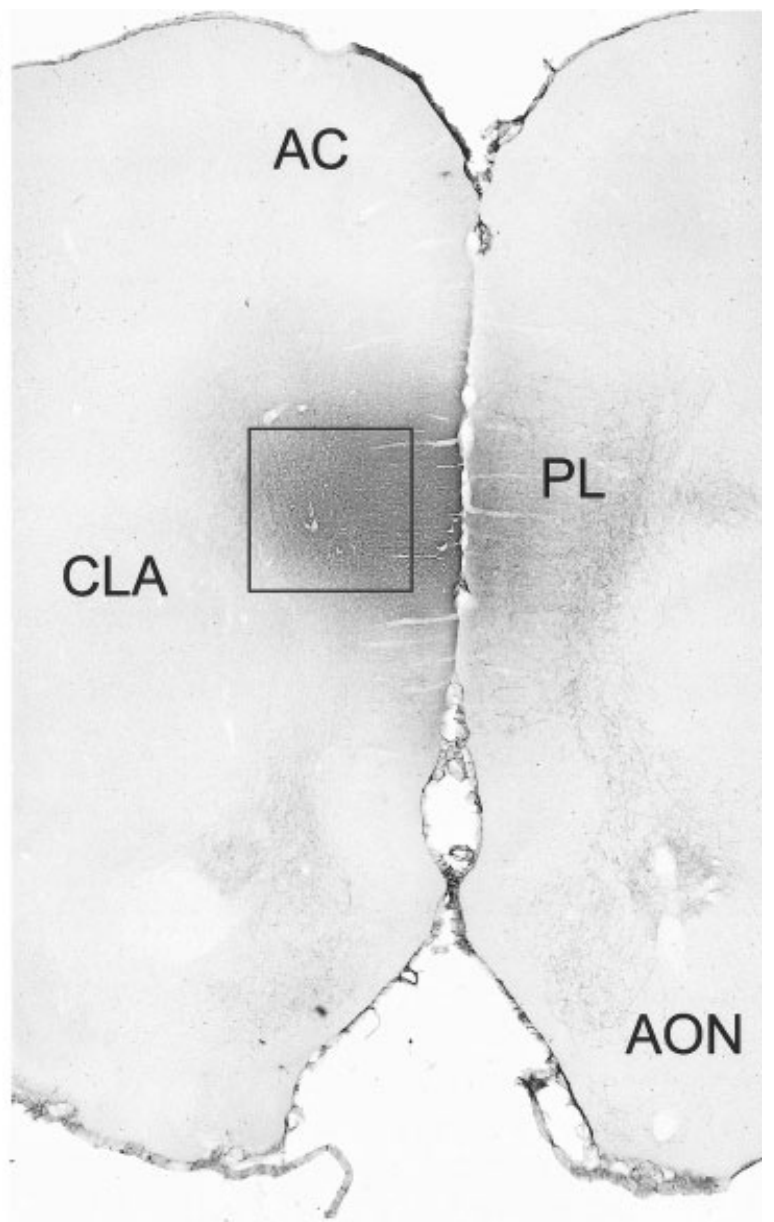

C

Fig. 1. A,B: Low-magnification lightfield photomicrographs showing the locations of Phaseolus vulgaris-leucoagglutinin (PHA-L) injections in the infralimbic (A) and prelimbic (B) cortices in the rat. Rectangles indicate the areas of PHA-L-filled cells in the respective injections. C: High-magnification lightfield photomicrograph showing
PHA-L filled cells in the prelimbic cortex (corresponds to rectangle in B). Note PHA-L labeled fibers coursing from the sites of injection to respective contralateral fields $(\mathbf{A}, \mathbf{B})$ and particularly prominent fibers from the prelimbic cortex (B) to the anterior olfactory nucleus, ipsilaterally and contralaterally. For abbreviations, see list. 

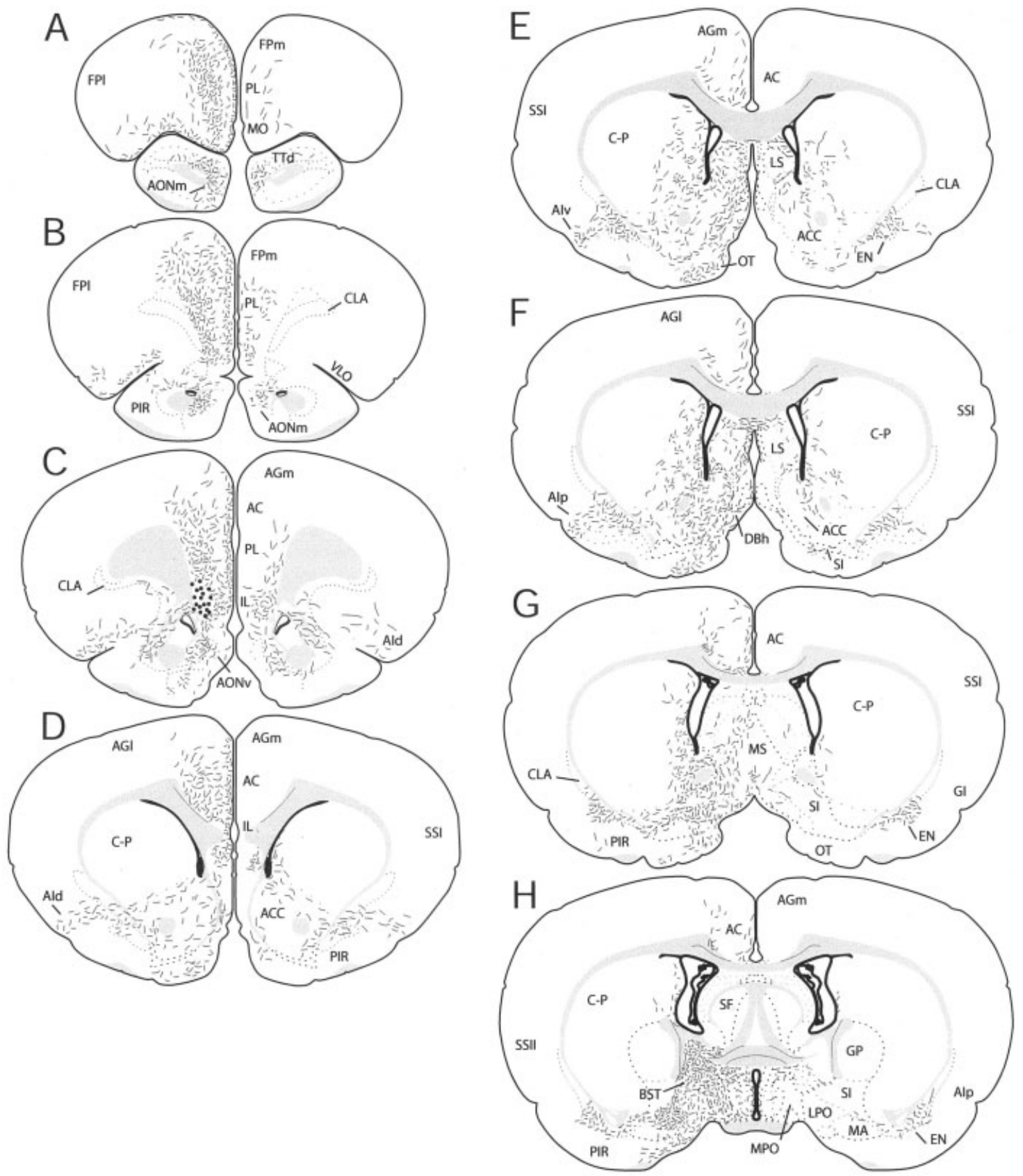

Fig. 2. Schematic representation of labeling present in selected sections through the forebrain and rostral brainstem (A-R) produced by a PHA-L injection (dots in C) in the infralimbic cortex (case 701). Sections modified from the rat atlas of Swanson (1998). For abbreviations, see list. (Figure 2 continued p. 38-39).

along the midline within PVp, IMD, and PH (Fig. 5A) as well as caudally in SUM (Fig. 5B,C).

Labeling continued to decline at the level of the brainstem (Fig. 2P-R). Main brainstem targets were medial/ventromedial regions of the periaqueductal gray (PAG), the substantia nigra-pars compacta (SNc), the interpeduncular nucleus, and the medial and lateral parabrachial nuclei (Fig. 2P,Q). The ventral tegmental area (VTA), dorsal raphe nucleus, Barrington's nucleus, the nucleus ambiguus (not shown), and nucleus of the solitary tract (not shown) were lightly to moderately labeled. Finally, at caudal levels of the cortex labeling was essentially confined to the lateral entorhinal cortex (bilaterally) (Fig. 2P$\mathrm{R})$.

\section{Differences in rostral and caudal IL projections}

Although patterns of projections from the rostral and caudal IL were largely similar, there were some notable differences. Rostral regions of IL distribute 

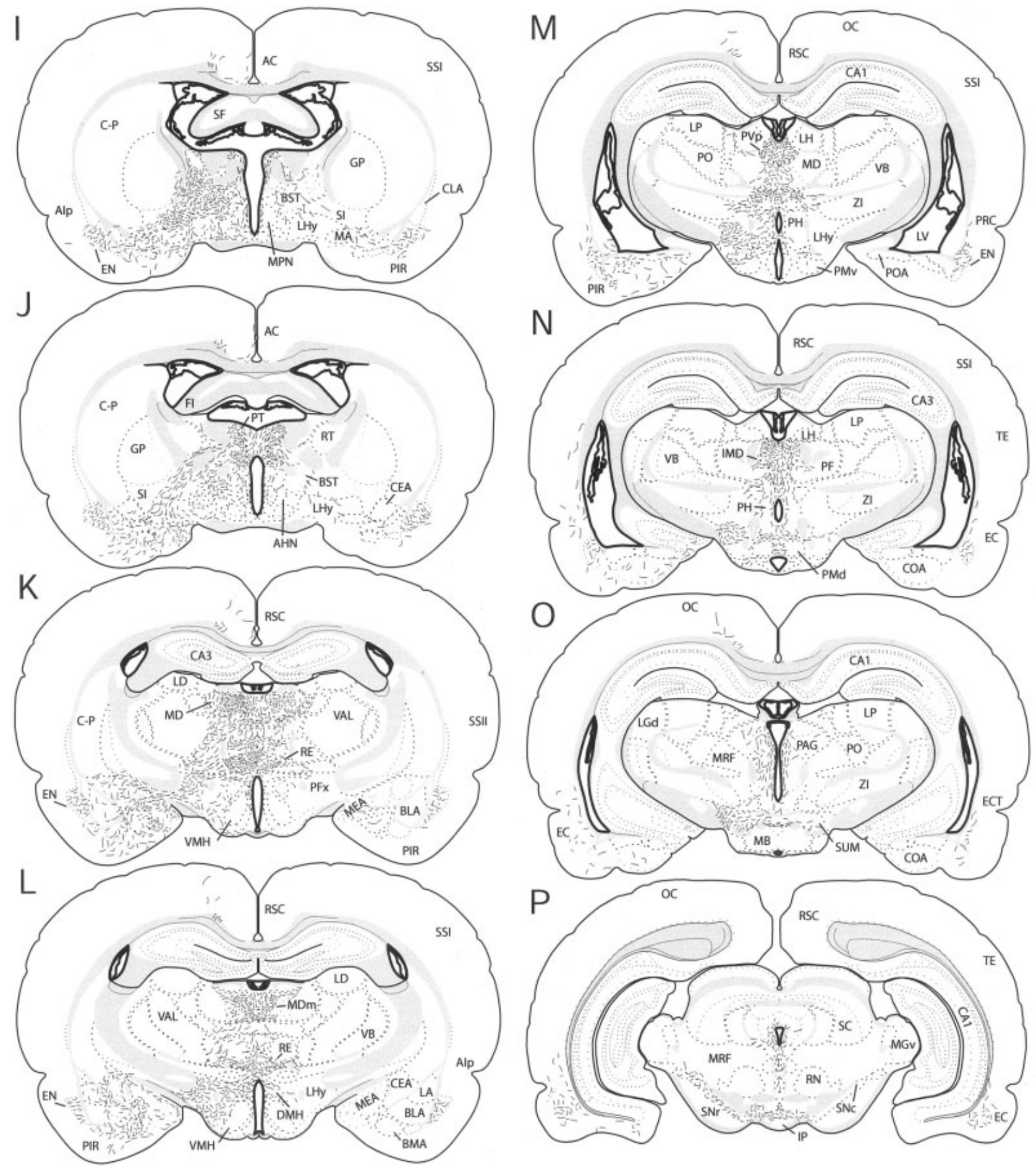

Figure 2 (Continued).

more heavily than caudal regions to the posterior insular cortex, the shell of ACC, BST, the central and basomedial nuclei of the amygdala, MDm, and EC. On the other hand, the caudal IL projects more heavily than the rostral IL to the lateral septum and $\mathrm{DBh}$, the anterior hypothalamus, the supramammil- lary nucleus, and the diencephalic and mesencephalic periventricular gray.

\section{Prelimbic cortex: case 668}

Figure 6 schematically depicts the distribution of labeled fibers throughout the brain following a 


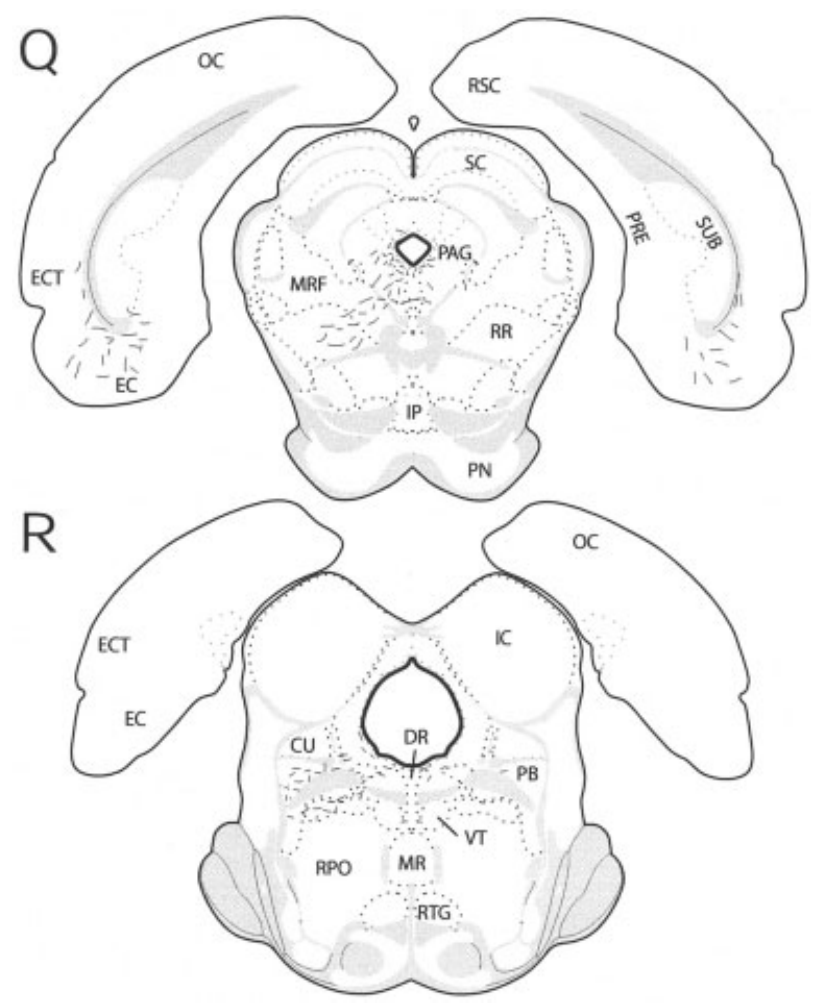

Figure 2 (Continued).

PHA-L injection in the prelimbic cortex. As shown (Fig. 1B,C), PHA-L-filled cells were restricted to layers 5 and 6 of PL.

Labeled fibers coursed forward from the site of injection (Fig. 6B,C) to distribute to the medial orbitofrontal cortex and olfactory structures of the anterior forebrain (Fig. 6A). Main terminal sites were FPm, anterior PL and $\mathrm{MO}$ of the medial prefrontal cortex, and the dorsal and ventral tania tecta, anterior piriform cortex, and anterior olfactory nucleus of the olfactory forebrain (Fig. 7A,B). Layer 1 of $\mathrm{VO}$ and VLO was lightly to moderately labeled.

Labeled fibers spread in several directions from the site of injection (Fig. 6B); that is, locally to PL, AC, and IL, ventrally to the anterior olfactory nucleus, TTd, TTv, and VO, and laterally to AId. Labeling was fairly uniform throughout all layers of $\mathrm{AC}, \mathrm{PL}$, and IL, but restricted to layers $5 / 6$ of VO. Figure 8 depicts labeling in the contralateral $\mathrm{mPFC}$, mainly localized to PL, at two levels of the anterior forebrain.

Further caudally (Fig. 6C), labeling remained pronounced in PL and IL, mainly concentrated in layers 1-3 and 6, bilaterally. A prominent bundle of labeled axons coursed laterally from PL to densely innervate the dorsal and ventral agranular insular cortices, stronger contralaterally (right side) than ipsilaterally. In addition, a dense array of labeled fibers capped the anterior commissure, localized to $\mathrm{AONv}$ and to the anterior part of nucleus accumbens. The OT was mod- erately labeled. This pattern of labeling is depicted in the photomontage of Figure 9.

Labeled fibers descended from the site of injection mainly through dorsomedial aspects of the cortex and through the medial striatum, distributing en route to $\mathrm{AC}$ and to dorsomedial parts of C-P, respectively, and beyond the striatum to ACC, OT, the claustrum (CLA) and AId (Fig. 6D,E). Both the shell and core of ACC were densely labeled. Figure 10 depicts pronounced labeling contralaterally in ACC, CLA and deep layers (5 and 6) of AId.

The primary targets of labeled fibers at the level of the septum (Fig. 6F,G) were AC, medial C-P, substantia innominata, CLA, OT, and DBh. C-P and CLA were heavily labeled; the other sites were lightly to moderately labeled. Unlike pronounced labeling rostrally in ACC, there was a virtual absence of labeled fibers in the caudal pole (medial shell) of ACC.

At the rostral diencephalon (Fig. 6H,I), a large contingent of labeled axons swept dorsomedially from the internal capsule into the thalamus to distribute heavily to the anterior PT, RE, and the medial division of $\mathrm{MD}$, and lightly to the paraventricular nucleus of thalamus; a second group took a more ventral course terminating lightly to moderately in LHy, CLA, and the basolateral nucleus of the amygdala. SI and ZI were sparsely labeled.

At mid-levels of the diencephalon (Fig. 6J,K), labeling was mainly restricted to MD and RE of thalamus and parts of the amygdala. Medial and lateral divisions of MD were heavily labeled; MDc was essentially devoid of labeled fibers. Within the amygdala, labeling was virtually confined to the central nucleus (dorsal capsular and lateral parts) and the basolateral nucleus-stronger contralaterally (right side) than ipsilaterally. Figure 11 depicts labeling contralaterally in CE and BLA at three levels of the amygdala. At these same levels, ZI, LHy, and CLA, were lightly to moderately labeled.

The virtually exclusive targets of labeled fibers at the caudal diencephalon (Fig. 6L,M) were the midline thalamus and the hypothalamus; that is, the lateral habenula, posterior PV (PVp), IMD, medial PF, and the central medial nucleus (CEM) of the thalamus, and LHy, the posterior nucleus (PH), the dorsal premammillary nucleus and SUM of the hypothalamus. The most heavily labeled sites were PVp, IMD, CEM, and $\mathrm{PH}$.

Labeled fibers primarily reached the brainstem via the mammillary peduncle (MP) (Fig. 6M-P). Significant numbers exited laterally from MP to moderately innervate SNc, while others continued caudally with MP to distribute to VTA, IP, the supralemniscal nucleus (B9), and the median raphe nucleus. A branch of this latter bundle arched dorsolaterally through the pontine tegmentum to fairly densely innervate ventromedial and lateral regions of PAG (including the pre- 


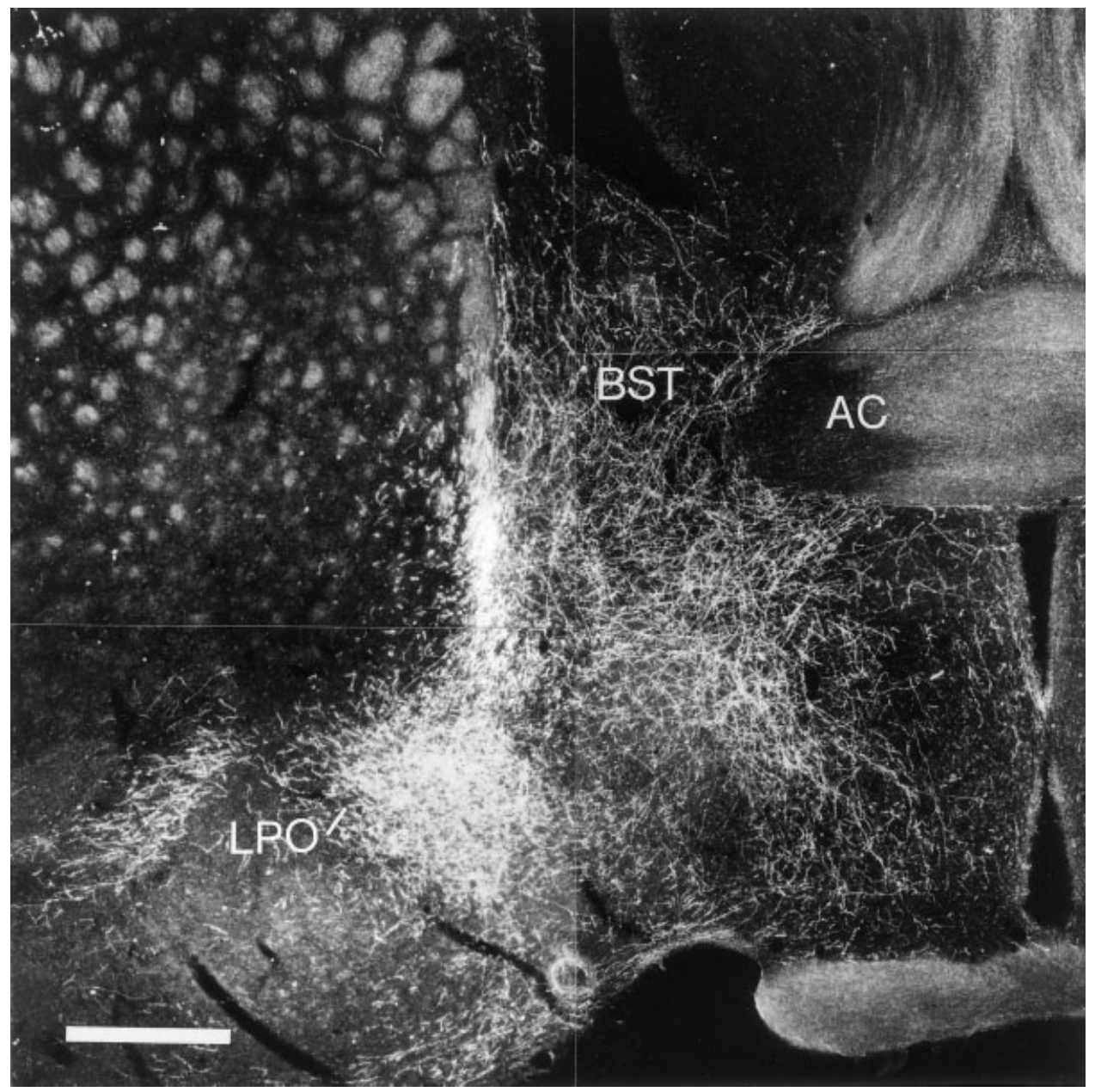

Fig. 3. Darkfield photomicrograph of a transverse section through the forebrain showing patterns of labeling in the basal forebrain produced by an injection in the infralimbic cortex (case 701). Note dense terminal labeling in the bed nucleus of the stria terminalis (BST), the ventral part of the lateral preoptic area (LPO), and the medially adjacent medial preoptic area. Scale bar $=600 \mu \mathrm{m}$. commissural nucleus) and the dorsal raphe nucleus. Finally, moderate labeling was observed in the piriform, perirhinal, and entorhinal cortices at caudal levels of the cortex.

\section{Differences in rostral/caudal and dorsal/ventral PL projections}

There were distinct differences in projections from the rostral and caudal PL. The rostral PL distributes more heavily than the caudal PL to the agranular insular cortex (deep and superficial layers), the entorhinal cortex, the core of ACC, the basolateral and central nuclei of the amygdala, MDm, SUM, PVp, and the dorsal raphe nucleus. On the other hand, the caudal PL projects more heavily than the rostral PL to the anterior cingulate cortex (supracollasal part), lateral septum, the anterior nucleus of the hypothalamus, the anteromedial and interanteromedial nuclei of the thalamus, MDl, RE, and the supralemniscal nucleus (B9). In addition, the rostral PL distributes fairly selectively to ventrolateral regions of the PAG and the caudal PL to the dorsolateral PAG.

Differences in dorsal and ventral PL projections largely depended on the proximity of injections to adjacent regions of the $\mathrm{MPFC}$ (AC for the dorsal PL; IL for the ventral PL); that is, the closer injections were to neighboring regions the stronger were common projections with respective regions. For instance, dorsal PL fibers distributed heavily to the posterior cingulate/retrosplenial cortex and the lateral MD (mirroring AC), while the ventral PL projected heavily to the $\mathrm{DBh}, \mathrm{MPO}$, and medial MD (mirroring IL). Based on previous reports of differential dorsal and ventral PL projections to the ventral striatum (nucleus accumbens) (Berendse et al., 1992; Groenewegen et al., 1999), we carefully examined PL projections to ACC and found only a slight tendency of dorsal PL fibers to distribute more heavily to the core than shell of ACC and ventral PL fibers to distribute more densely to the shell than core of ACC, rather than a clear separation of dorsal and ventral PL projections to parts of ACC as previously described (Berendse et al., 1992).

\section{DISCUSSION}

We compared and contrasted projections from the infralimbic and prelimbic cortices in the rat. With the exception of projections to the thalamus and 


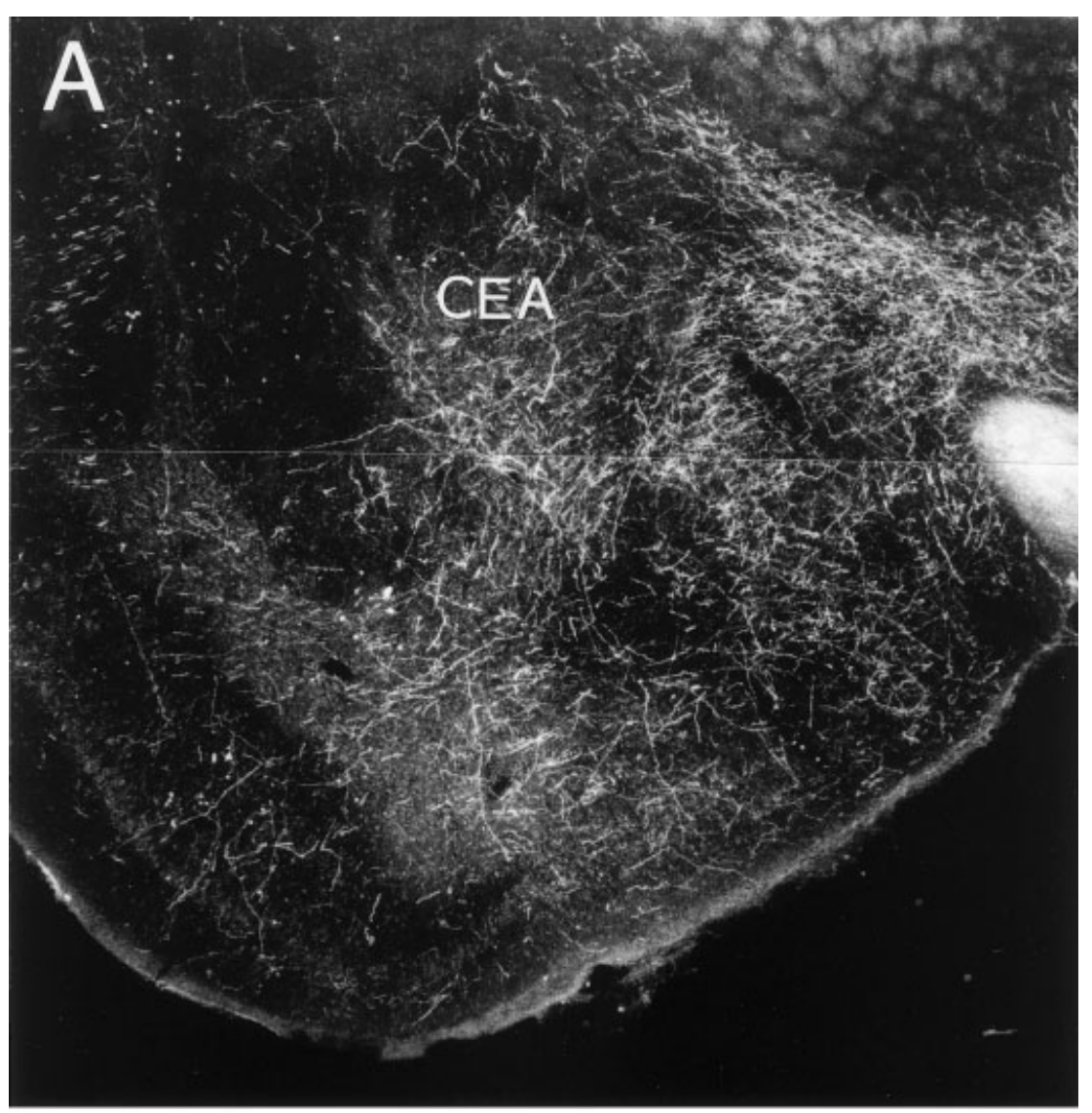

Fig. 4. Darkfield photomicrograph of a transverse section through the forebrain showing patterns of labeling in the amygdala produced by an injection in the infralimbic cortex (case 701). Note pronounced labeling in the central (A), medial $(\mathbf{A}, \mathbf{B})$, and basomedial $(\mathbf{A}, \mathbf{B})$ nuclei, and an essential absence of labeling in the lateral and basolateral nuclei, lateral to the central nucleus. Scale bar $=600 \mu \mathrm{m}$.

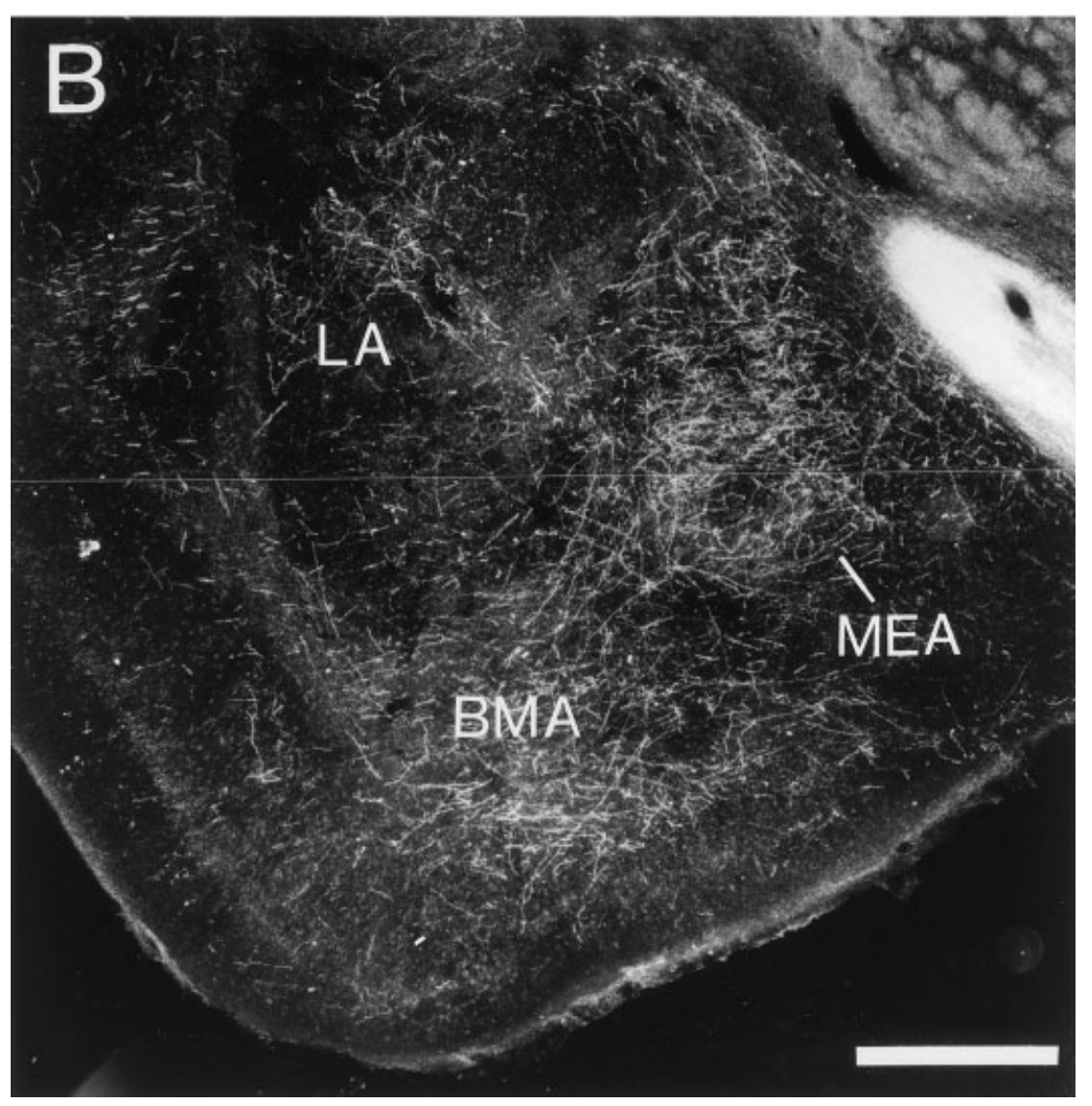




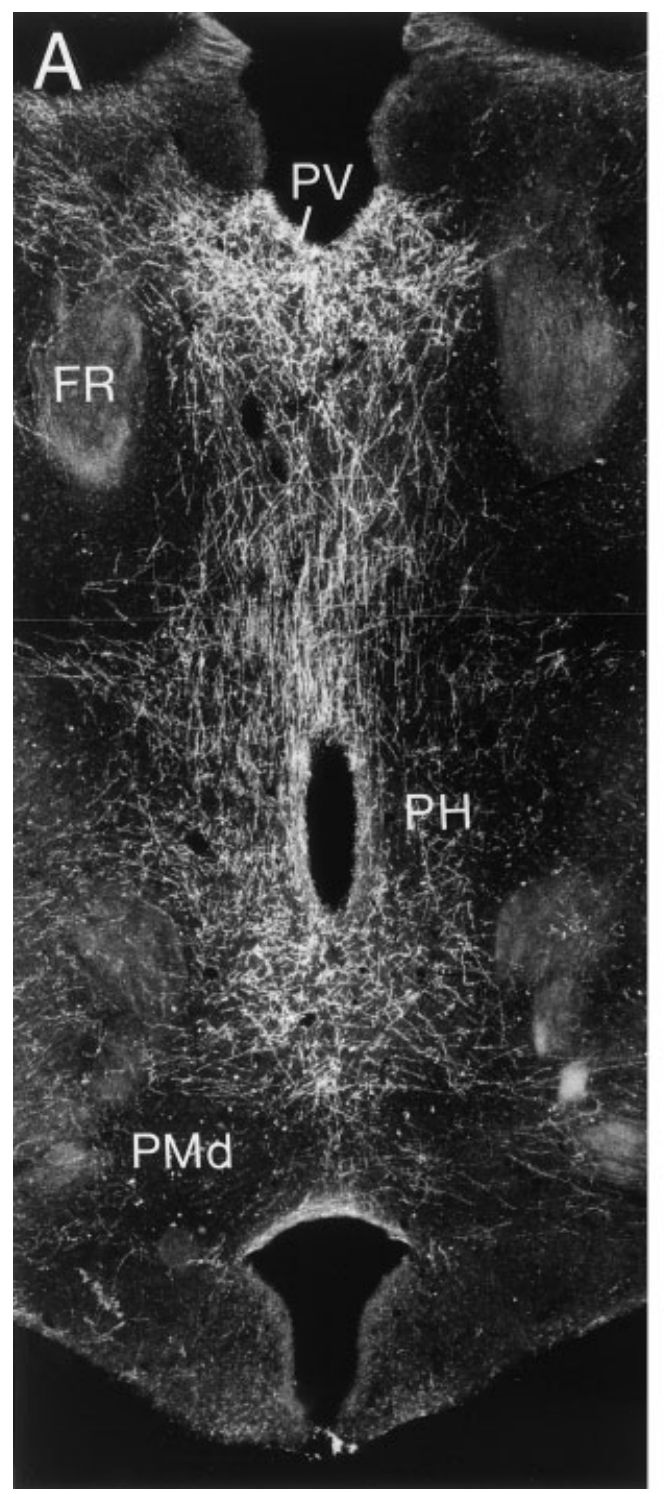

Fig. 5. Darkfield photomicrographs of transverse sections through the diencephalon showing patterns of labeling in caudal regions of the thalamus and hypothalamus. A: Pronounced labeling dorsoventrally along the midline in the paraventricular nucleus (PV) and intermediodorsal nucleus of thalamus (ventral to PV) and the posterior nucleus

parts of the olfactory forebrain and cortex, IL and PL distribute very differently throughout the brain. These differential patterns of projections undoubtedly reflect functional differences between IL and PL. The projections of IL are consistent with its involvement in visceromotor functions, functionally homologous to the orbitomedial PFC of primates (Neafsey, 1990; Barbas, 1995, 2000; Groenewegen and Uylings, 2000), whereas those of PL are consistent with a role in cognitive processes, functionally homologous to the dorsolateral prefrontal cortex of primates (Kolb, 1984; Goldman-Rakic, 1987, 1995; Groenewegen and Uylings, 2000).
(PH) of the hypothalamus. B,C: Labeling rostrally (B) and caudally (C) in the supramammillary nucleus (SUM), densest in the medial nucleus of SUM. Note absence of labeling in all parts of the mammillary complex (A-C) including the dorsal premammillary nucleus (PMd). Scale bar $=600 \mu \mathrm{m}$.

\section{Projections of the infralimbic cortex}

The primary targets of IL fibers were: 1 ) the medial prefrontal (FPm, AC, PL, IL), orbital (mainly MO), insular, and entorhinal cortices; 2) the anterior piriform cortex, dorsal and ventral tania tecta, and anterior olfactory nucleus of the olfactory forebrain; 3) LPO, lateral aspects of MPO, SI, BST, LS, DBh, and endopiriform nucleus of the basal forebrain; 4) the medial, basomedial, cortical and central nuclei of the amygdala; 5) the PT, PV, MD, IMD, IAM, CEM, and RE of the thalamus; 6) the dorsomedial, lateral, perifornical, posterior, and supramammillary nuclei of the hypothalamus; and 7) the SNc, PAG, $\mathrm{PB}$, and NTS of the brainstem (Table I, Fig. 12A). 

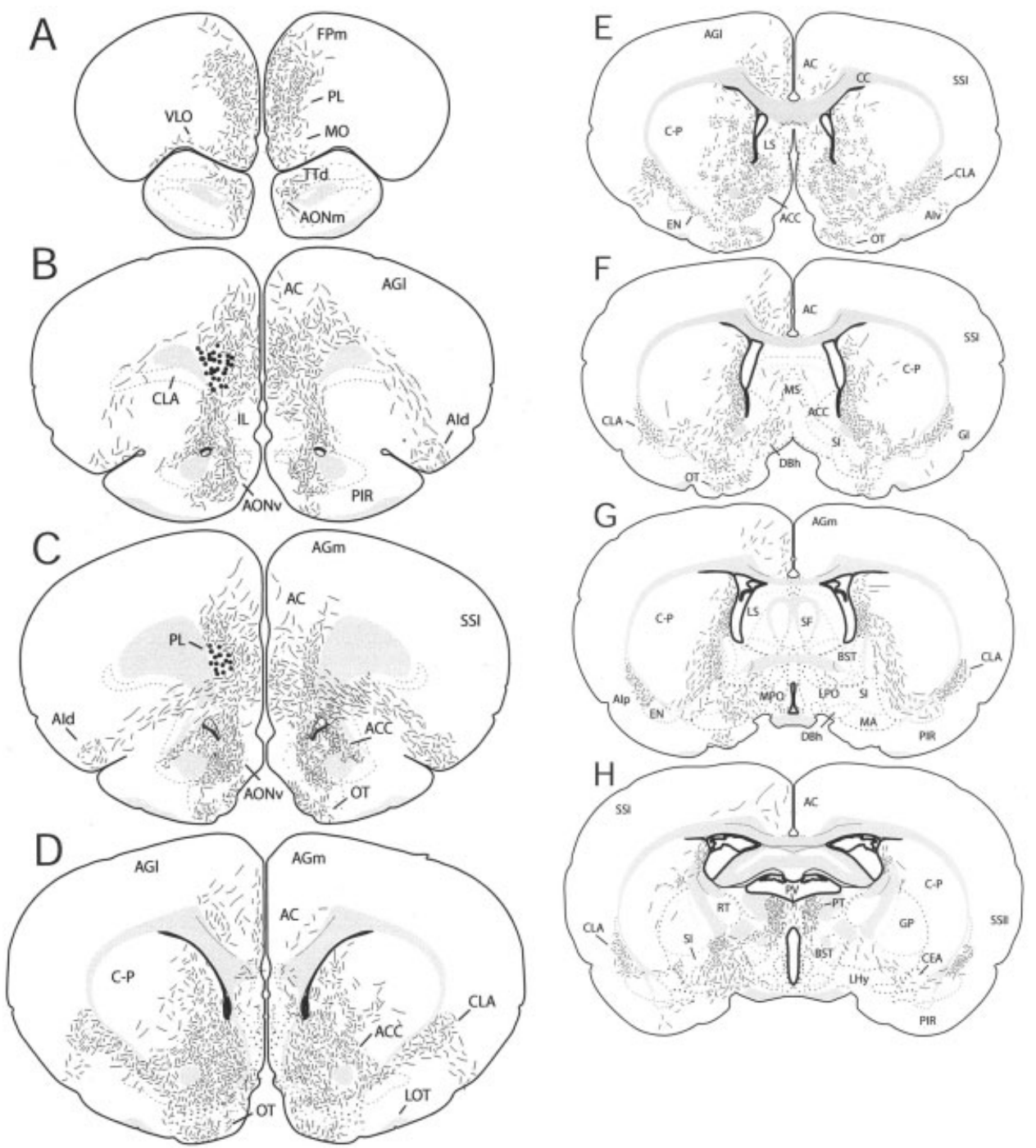

Fig. 6. Schematic representation of labeling present in selected sections through the forebrain and rostral brainstem (A-P) produced by a PHA-L injection (dots in B,C) in the prelimbic cortex (case 668). Sections modified from the rat atlas of Swanson (1998). For abbreviations, see list. (Figure 6 continued p. 44).

\section{Projections of the prelimbic cortex}

The main targets of PL fibers were: 1) FPm, IL, AC, $\mathrm{MO}, \mathrm{AI}$ (dorsal and ventral divisions), and EC of the cortex; 2) the anterior PIR, AONm,v, and TTd of the olfactory forebrain; 3) medial C-P, the nucleus accumbens (shell and core), OT, and CLA of the basal forebrain; 4) PT, PV, AM, IAM, CEM, MD-IMD, and RE of the midline thalamus; 5) the central and basolateral nuclei of the amygdala; and 6) VTA, SNc, PAG, supralemniscal nucleus (B9), DR, and MR of the brainstem (Table I, Fig. 12B).

\section{Common IL and PL projections}

Despite largely separate patterns of projections, IL and PL distribute commonly to some sites, mainly to the midline/medial thalamus. Both IL and PL project heavily (and bilaterally) to the paratenial, paraventricular, $\mathrm{MD} /$
IMD, IAM, CEM, and nucleus reuniens of the midline thalamus. In addition, IL and PL project commonly to the anterior PIR, AONm,v, and dorsal and ventral tania tecta of the olfactory forebrain, and to parts of the orbitomedial, insular, and entorhinal cortices. PL distributes much more heavily than IL to the insular cortex.

\section{IL and PL projections: comparisons with previous studies}

\section{mPFC and adjacent regions of the prefrontal cortex}

We showed that IL and PL distribute significantly to other subdivisions of the orbitomedial PFC; that is, densely to IL, PL, and AC and moderately to AGm and parts of the orbital cortex (MO, VO, and VLO). 

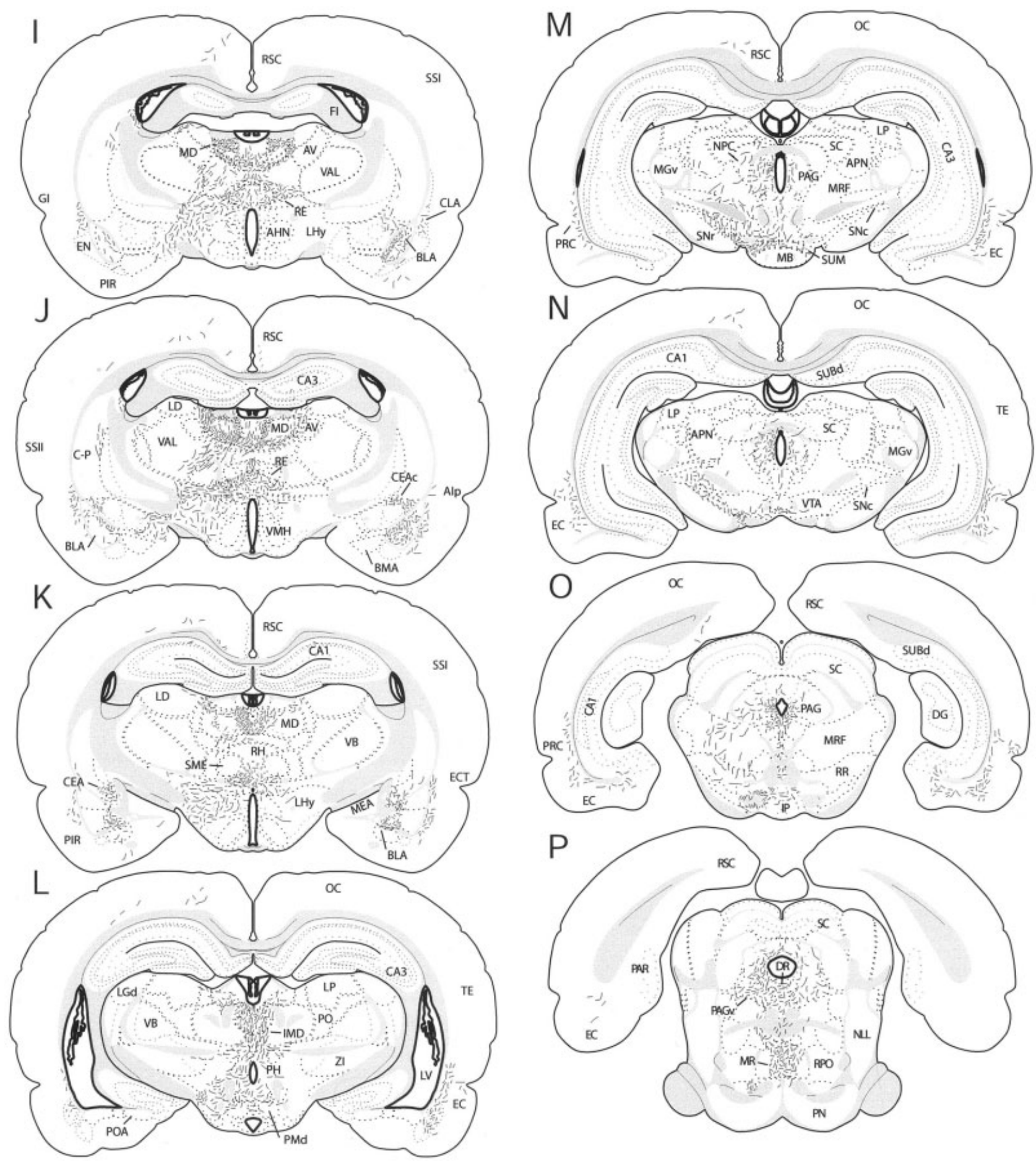

Figure 6 (Continued).

With few exceptions, previous studies have similarly demonstrated pronounced IL/PL projections to neighboring regions of the orbitomedial PFC. For instance, Takagishi and Chiba (1991) reported that IL fibers distribute widely throughout the $\mathrm{mPFC}$; that is, to the medial precentral, PL, and dorsal peduncular cortices, as well as to rostral pole of VO and VLO. Hurley et al. (1991) demonstrated comparable results for IL, and further noted that "control" injections in PL resulted in "extensive projections to all cortical areas located along the medial surface of the frontal lobe including layers I, II, III, and V of the medial orbital cortex, the tania tecta, the dorsal peduncular cortex, the ILC, and the anterior cingulate cortex." Consistent with this, Sesack et al. (1989) found that PL fibers distribute to several regions adjacent to PL, including the rostrocaudal ex- 

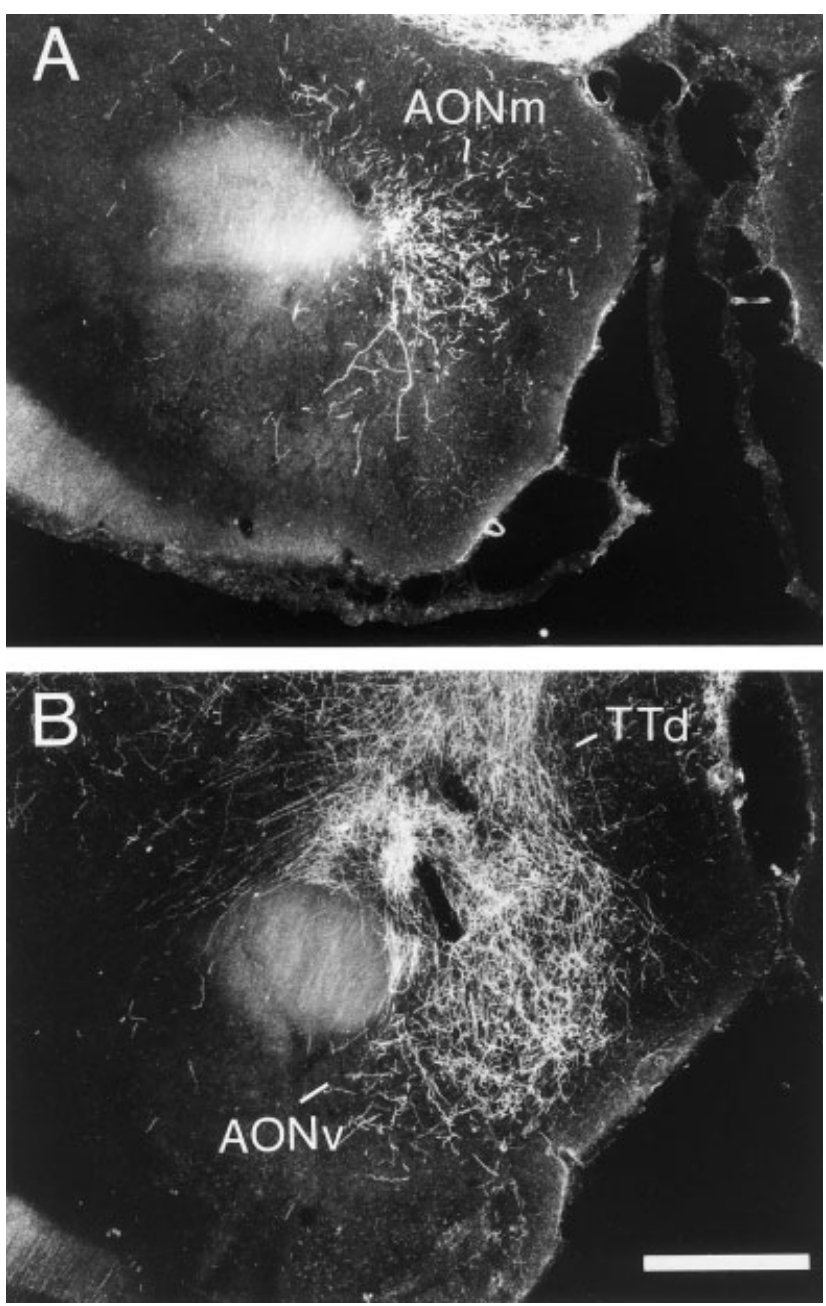

Fig. 7. Darkfield photomicrographs of transverse sections through rostral forebrain showing patterns of labeling in the anterior olfactory complex produced by an injection in the prelimbic cortex (case 668). Note pronounced labeling in the anterior medial olfactory nucleus $(\mathrm{AONm})$, rostrally $(\mathbf{A})$ and the dorsal tania tecta (TTd) and the anterior ventral olfactory nucleus $(\mathrm{AONv})$, caudally $(\mathbf{B})$. Scale bar $=$ $600 \mu \mathrm{m}$.

tent of the prelimbic and dorsal anterior cingulate cortices as well as to the medial precentral and infralimbic cortices. In contrast to the foregoing, Fisk and Wyss (1999) recently described fairly limited interconnections among subdivisions of the mPFC. It appears, however, that the injections of Fisk and Wyss (1999) were quite small, possibly resulting in a more restricted distribution of IL and PL fibers than shown in previous reports.

\section{Insular cortex (INC)}

We showed that IL and PL project very differently to the INC. PL distributes much more heavily than IL to INC, and PL fibers are mainly directed to the rostral agranular insular cortex (dorsal and ventral divisions), and IL fibers to the posterior agranular INC.

In accord with the present findings, Hurley et al. (1991) reported that the IL projection to INC was a relatively minor pathway, and remarked, in fact, that a reexamination of their earlier work (Saper, 1982a) revealed that $\mathrm{mPFC}$ cells retrogradely labeled from INC were "actually just beyond the border of IL, in the prelimbic cortex." A comparison of IL and PL projections in cats (Room et al., 1985) demonstrated considerably stronger PL than IL projections to INC, and further showed that PL fibers selectively target the rostral agranular INC. PL also distributes fairly selectively to AId in rats (Beckstead, 1979; Sesack et al., 1989). Finally, Shi and Cassell (1998) recently demonstrated that the agranular INC distributes to PL and the posterior INC to IL, indicating topographically organized reciprocal projections between IL/PL and INC.

\section{Claustrum (CLA) and endopiriform nucleus (EN)}

We showed that IL projects to the endopiriform nucleus and PL to the claustrum of the claustrum/endopiriform complex. The claustrum consists of two main zones-the dorsal (or insular) claustrum and the ventral (or piriform) claustrum, also termed the endopiriform nucleus. It is well documented that CLA/EN is reciprocally linked to virtually all areas of the cortex (Markowitsch et al., 1984; Sloniewski et al., 1986; Sherk, 1988; Witter et al., 1988; Kowianowski et al., 1998; Majak et al., 2000; Zhang et al., 2001).

Although a few reports have described projections from the PFC to parts of the claustrum (Markowitsch et al., 1984; Witter et al., 1988; Majak et al., 2000), to our knowledge none have examined possible differential IL and PL projections to CLA/EN. Despite this, an early anatomical analysis of IL (Hurley et al., 1991) demonstrated terminal IL labeling in EN, but interestingly, none in CLA (see their fig. 3A, p. 254), while an examination of PL (Sesack et al., 1989) showed the reverse: PL projections to CLA but not to EN (see their fig. 4, p. 220). In accord with the foregoing, Levesque and Parent (1998) recently showed that a subpopulation of PL cells project, via collaterals, to the claustrum and striatum, while Zhang et al. (2001) demonstrated that injections of retrograde tracers in the anterior CLA produced significant labeling in PL but virtually none in IL.

\section{Nucleus accumbens (ACC)}

We showed that IL and PL project very differently to ACC. PL fibers distribute massively throughout the core and shell regions of ACC. By contrast, IL fibers project fairly selectively to the caudo-medial sector (shell) of ACC.

PFC projections to ACC have been well documented (Beckstead et al., 1979; Newman and Winans, 1980; Groenewegen et al., 1982; McGeorge and Faull, 1989; Sesack et al., 1989; Hurley et al., 1991; Berendse et al., 1992; Brog et al., 1993; Phillipson and Griffiths, 1985; 

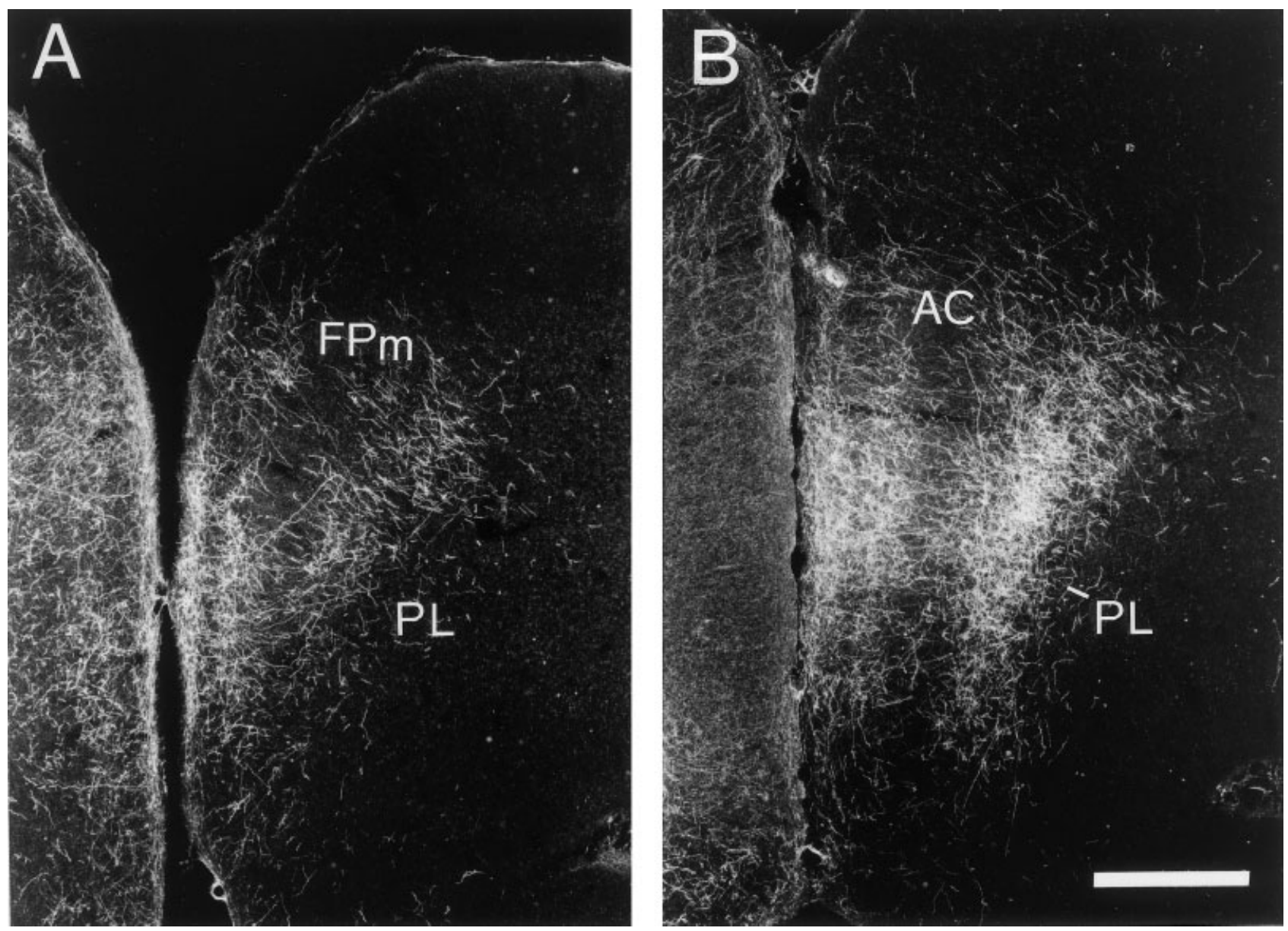

Fig. 8. Darkfield photomicrographs of transverse sections through the rostral forebrain depicting labeling contralaterally in the medial prefrontal cortex produced by an injection in the prelimbic cortex (case 668). Note pronounced labeling in all layers of the contralateral prelimbic cortex (PL), most heavily concentrated in layers $1 / 2$ and 5/6, as well as significant labeling in the frontal polar (FPm) cortex (A) and the anterior cingulate (AC) cortex $(\mathbf{B})$, dorsal to PL. Scale bar $=600 \mu \mathrm{m}$.

Room et al., 1985; Wright and Groenewegen, 1995, 1996; Montaron et al., 1996; Gorelova and Yang, 1997; Ding et al., 2001; French and Totterdell, 2002).

In accord with present findings, $\mathrm{mPFC}$ projections to ACC appear to primarily originate from PL of PFC (Beckstead et al., 1979; Sesack et al., 1989; Berendse et al., 1992; Brog et al., 1993; Montaron et al., 1996). For instance, Sesack et al. (1989) described a pattern of PL projections to ACC virtually identical to that shown here; that is, pronounced labeling throughout ACC, excluding the caudal shell of ACC. In like manner, a comprehensive analysis of PFC-striatal projections in rats (Berendse et al., 1992) showed that IL fibers mainly target the medial shell of ACC, whereas PL fibers distribute throughout extent of ACC, terminating more heavily in the core than shell of ACC. The PL-ACC projections described by Berendse et al. (1992) were, however, less robust than shown by others (Beckstead et al., 1979; Sesack et al., 1989, present results). Differences probably involve relative locations of injections across studies, as suggested by Sesack et al.'s
(1989) demonstration of marked variations in the density of labeling in ACC with injections in different parts of PL.

\section{BST and other structures of the medial basal forebrain}

We found that IL and PL project very differently to the basal forebrain. IL distributes significantly to the anterior part of the lateral septum, DBh, BST, SI, lateral MPO and LPO, whereas PL projects sparingly to each of these sites.

Consistent with this, an early comparison of IL/PL projections in cats (Room et al., 1985) demonstrated dense IL, but minimal PL, projections to the rostral septum, medial, and lateral preoptic area, diagonal band nuclei, BST, and SI. In like manner in rats, Takagishi and Chiba (1991) showed that IL distributes heavily to medial aspects of the lateral septum, the diagonal band nuclei, LPO, BST, and SI, while Hurley et al. (1991) described virtually the same, drawing 


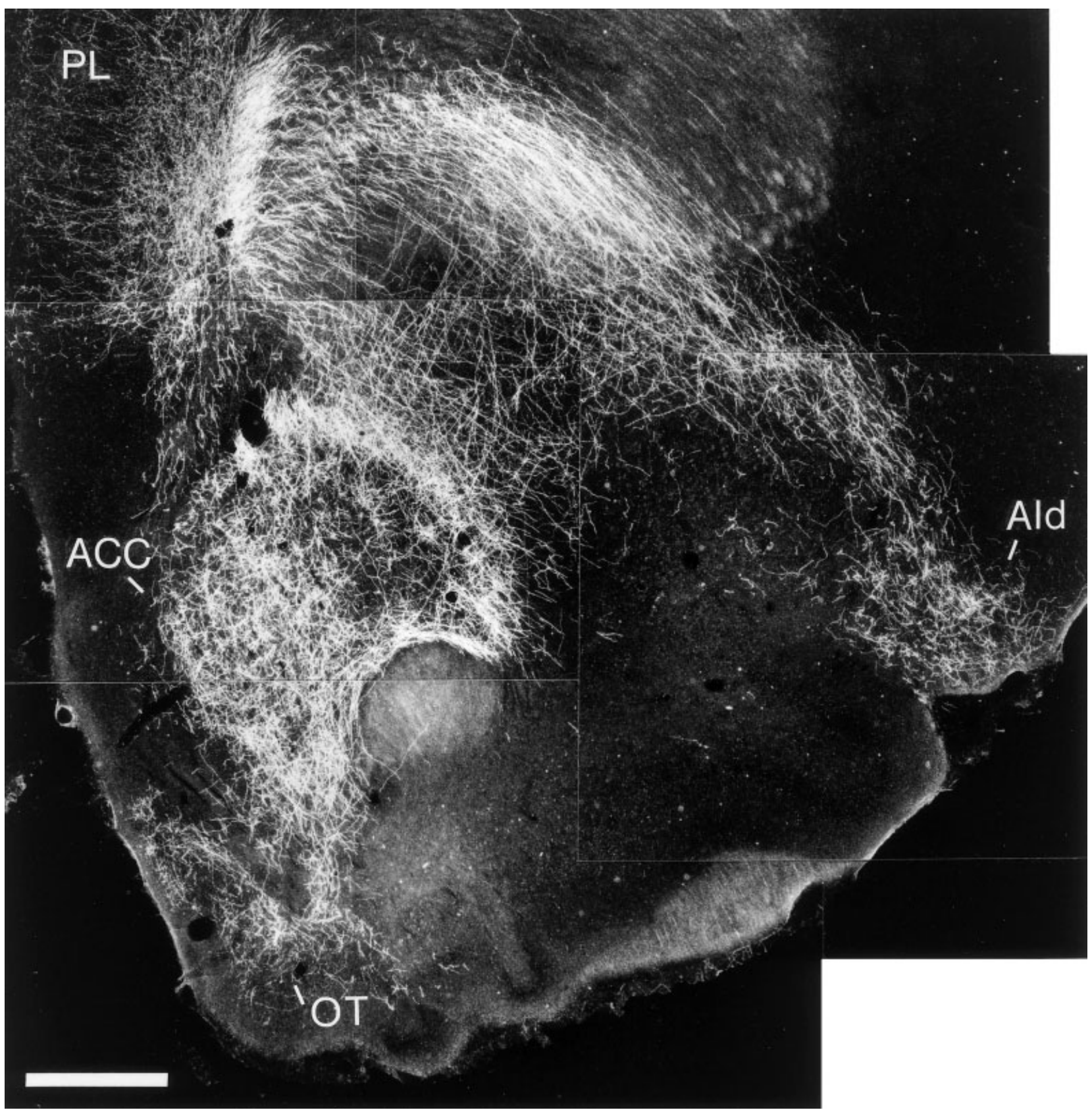

Fig. 9. Darkfield photomicrograph of a transverse section through the rostral forebrain showing labeling contralaterally in the forebrain produced by an injection in the prelimbic cortex (case 668). Note dense collection of ventrolaterally oriented labeled fibers terminally bound for the dorsal agranular insular cortex (AId). Note also massive labeling throughout the extent (shell and core) of the anterior pole of nucleus accumbens (ACC) as well as significant labeling in the ventrally adjacent olfactory tubercle (OT). Scale bar $=600 \mu \mathrm{m}$. particular attention to strong IL projections to MPO and BST.

Unlike IL, Sesack et al. (1989) showed that injections of PHA-L into various regions of PL produced an essential absence of labeling within the basal forebrain. For instance, they described a minor PL input to the medial septum, DBv, ventral pallidum, and SI and noted that only "sparse fibers-of-passage were visible in the bed nucleus of the stria terminalis."
Finally, injections of retrograde tracers in BST (Hurley et al., 1991), SI (Russchen et al., 1985; Grove, 1988a), and the horizontal and vertical limbs of the diagonal band (Carnes et al., 1990) have been shown to produce significant cell labeling IL but virtually none in PL.

\section{Amygdala}

We showed that IL and PL project very differently to the amygdala. IL fibers distribute widely through- 


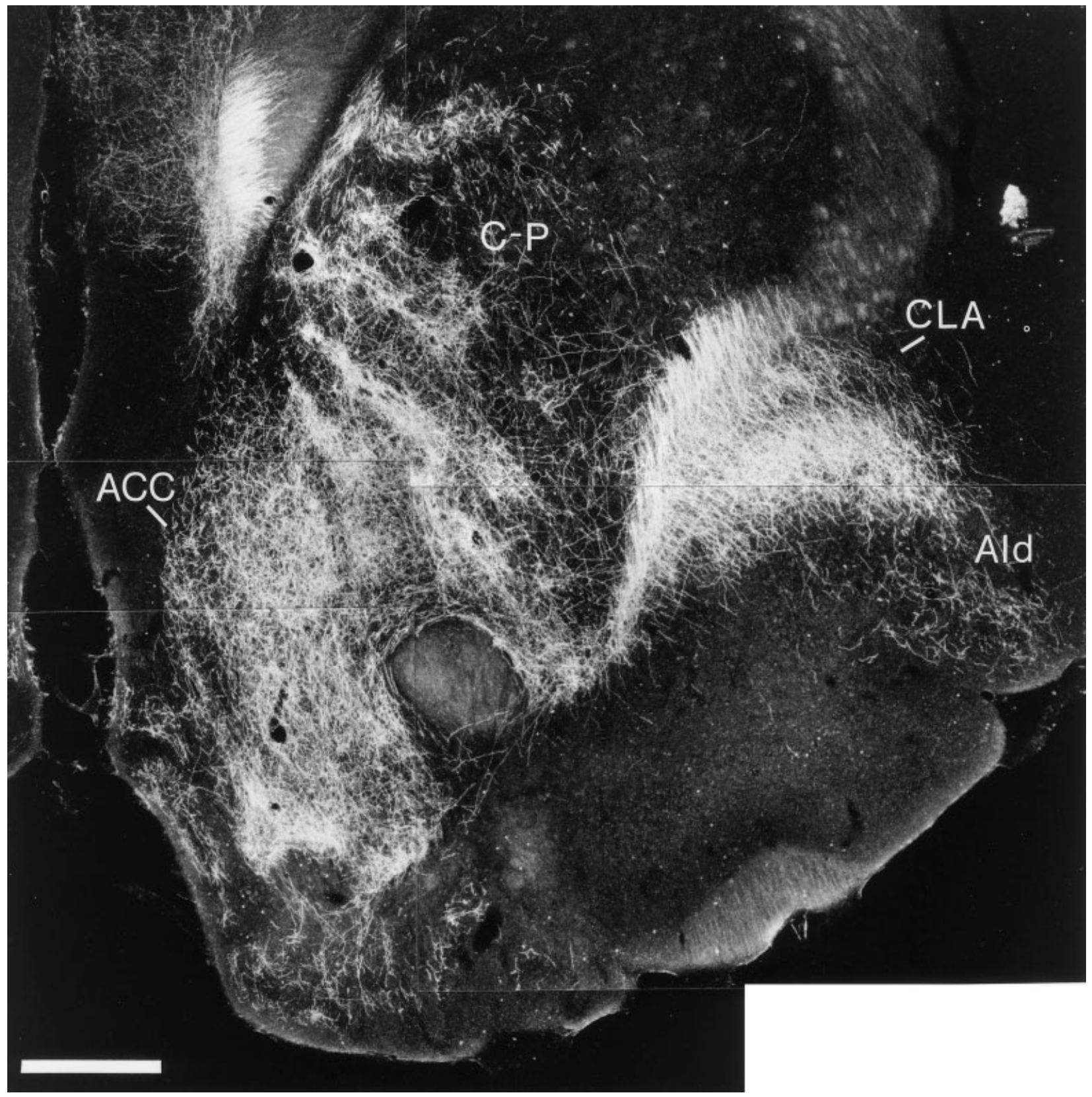

Fig. 10. Darkfield photomicrograph of a transverse section through the rostral forebrain depicting labeling contralaterally in the forebrain produced by an injection in the prelimbic cortex (case 668). Note dense terminal labeling in the claustrum (CLA), dorsal agranular insular cortex (AId), ventromedial striatum (C-P), and the shell and core regions of nucleus accumbens (ACC). Scale bar $=600 \mu \mathrm{m}$.

out the anterior two-thirds of the amygdala, mainly to rostral MEA, the capsular and medial subdivisions of CEA, and to the basomedial nucleus. By contrast, PL fibers selectively target the central nucleus (capsular portion) and the basolateral nucleus of the amygdala.

Hurley et al. (1991) described moderately dense IL projections to the central (medial aspects), medial, basomedial and anterior cortical nuclei of the amygdala, and a virtual absence of projections to the lateral and basolateral nuclei, while McDonald et al. (1996) re- ported that IL fibers distribute to "all major portions of the amygdala." They noted particularly heavy IL projections to the lateral capsular portion of CEA, BMA, and medial part of the lateral nucleus (McDonald et al., 1996).

An early study in rats (Beckstead, 1979) demonstrated significant PL projections to the lateral and basolateral nuclei of amygdala and to the region surrounding, but not in, CEA (i.e., to capsular CEA), while one in cats (Room et al., 1985) showed that PL projections were "restricted to the basolateral and central 

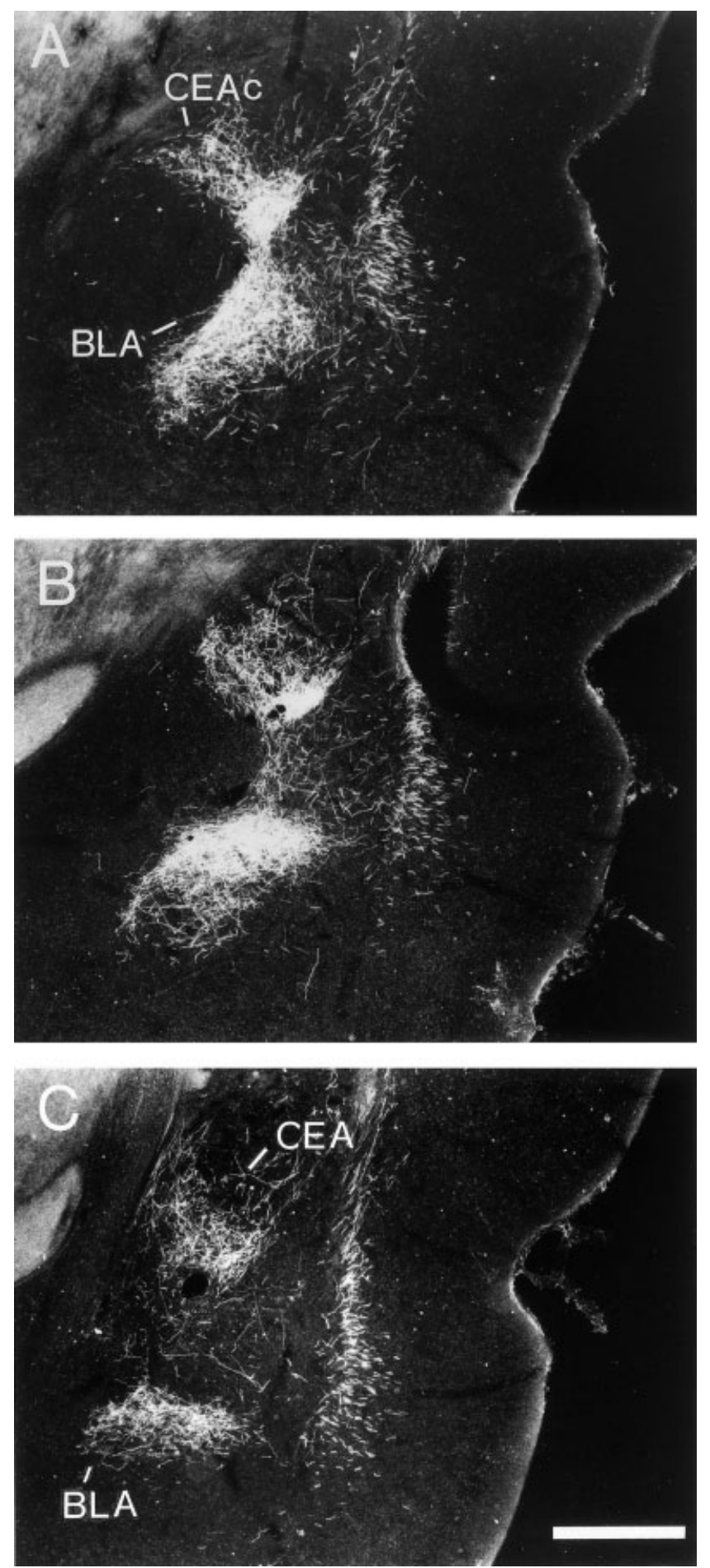

Fig. 11. Darkfield photomicrographs of transverse sections through the forebrain showing patterns of labeling contralaterally at three rostrocaudal (A-C) levels of the amygdala produced by an injection in the prelimbic cortex (case 668). Note dense labeling predominantly restricted to the capsular part of the central nucleus (CEAc) and the basolateral (BLA) nuclei of amygdala. Scale bar $=600 \mu \mathrm{m}$.

nuclei." More recently, Sesack et al. (1989) reported that PL fibers distribute selectively to the zone surrounding CEA (capsular CEA) and to the lateral, baso- lateral, and intercalated nuclei of amygdala, while McDonald et al. (1996) demonstrated that PL targets the anterior amygdaloid area, medial/dorsomedial BLA, and the capsular (mainly lateral capsular) CEA.

In summary, previous findings support the present demonstration that IL distributes widely throughout the amygdala; by contrast, PL fibers primarily project to the capsular CEA and BLA, and less so to the anterior, lateral, and intercalated nuclei of amygdala.

\section{Thalamus}

Unlike most other regions of the brain, we showed that IL and PL distribute commonly to the thalamus, predominantly to structures of the midline/medial thalamus. Both IL and PL project heavily to the paratenial (PT), paraventricular (PV), anteromedial (AM), interanteromedial (IAM), mediodorsal (MD), intermediodorsal (IMD), reuniens (RE), and central medial nuclei (CEM) of thalamus, and moderately to the parafascicular and rhomboid nucleus.

Our findings are consistent with previous anterograde analyses of IL and PL projections to the thalamus (Beckstead, 1979; Room et al., 1985; Sesack et al., 1989; Hurley et al., 1991; Takagishi and Chiba, 1991; Buchanan et al., 1994; Vertes, 2002), as well as with retrograde examinations of afferents to PT-PV (Chen and Su, 1990; Hurley et al., 1991; Risold et al., 1997), IMD-MD (Groenewegen, 1988; Cornwall and Phillipson, 1988; Hurley et al., 1991), RE (Herkenham, 1978; Hurley et al., 1991; Risold et al., 1997), and AM (Seki and Zyo, 1984).

\section{Hypothalamus}

We showed that IL and PL project very differently to the hypothalamus. IL projects significantly to the dorsomedial hypothalamic nucleus/area, the lateral hypothalamus, perifornical region, posterior and supramammillary nuclei. By contrast, PL fibers mainly traverse the hypothalamus en route to the brainstem, distributing lightly in transit to $\mathrm{PH}$, SUM, and parts of LHy.

Hurley et al. (1991) described significant IL projections to LHy, PFx, DMH, PH, and SUM of the hypothalamus, and further noted that "control" injections in PL produced relatively scant labeling in the hypothalamus, sparsely distributed to the lateral hypothalamus. In like manner, Room et al. (1985) showed for cats that IL distributes densely, PL lightly, to the septum, medial preoptic area, and dorsomedial and lateral hypothalamus. In slight contrast to the foregoing, Sesack et al. (1989) reported that a PHA-L injection in the rostroventral PL produced moderate labeling in $\mathrm{LHy}$, SUM, and medial MB. They pointed out, however, that this injection spread to the underlying IL and medial orbital cortices, which could have contributed to the hypothalamic labeling observed with this case. Injec- 
tions in other parts of PL resulted in an essential absence of labeling in the hypothalamus (Sesack et al., 1989). Consistent with these findings, we observed a similar dorsal-ventral gradient in PL projections to the hypothalamus from an essential absence of hypothalamic projections with dorsal injections to light (and in some cases) moderate hypothalamic labeling with ventral PL injections, bordering IL.

Finally, Floyd et al. (2001) recently demonstrated that the rostroventral IL/PL projects to the dorsal hypothalamic area, LHy, lateral $\mathrm{PFx}$, and $\mathrm{PH}$, while the caudoventral IL/PL projects to these sites as well as to the dorsolateral AHN, the dorsal hypothalamic nucleus and medial PFx.

\section{Brainstem}

With some overlap, IL and PL largely distribute to separate sites in the brainstem. IL mainly targets SNc, dorsal aspects of IP, ventrolateral regions of the pontomesencephalic PAG, the medial and lateral parabrachial nuclei and NTS. PL primarily distributes to VTA, SN (pars compacta and reticulata), precommissural nucleus (PCO), the lateral and ventrolateral pontine PAG, the supralemniscal nucleus (B9) (Vertes and Crane, 1997), and the dorsal and median raphe nuclei. PL distributes more heavily than IL to common targets: VTA, SNc, and ventrolateral PAG. PL fibers spread mediolaterally throughout SNc, whereas IL fibers predominantly terminated in the medial one-third of SNc.

Several early reports (Ross et al., 1981; Saper, 1982b; Terreberry and Neafsey, 1983, 1987; van der Kooy et al., 1984; Neafsey et al., 1986b; van Bockstaele et al., 1989; Moga et al., 1990a) showed that IL fibers strongly (and fairly selectively) target autonomic/visceral-related nuclei of the brainstem; specifically, the ventrolateral PAG, PB, Barrington's nucleus, NTS, and the rostral ventrolateral medulla. Hurley et al. (1991) confirmed these results, and further demonstrated IL projections to the nucleus ambiguus (NA) and to the dorsal motor nucleus of the vagus (DMV). In partial contrast with the foregoing, we demonstrated moderate IL projections to "autonomic-related" nuclei of the upper brainstem (e.g., parabrachial nucleus), and sparse projections to those of the lower brainstem including NA, NTS, and DMV.

By comparison with IL, PL fibers distribute more widely throughout the pons and midbrain, and with the exception of PAG, largely avoid autonomic nuclei of the brainstem (Beckstead, 1979; Sesack et al., 1989; Floyd et al., 2000). In general accord with present findings, Beckstead (1979) described prominent PL projections to SNc and the adjoining VTA and significant but less dense ones to DR and MR, while Sesack et al. (1989) traced PL fibers to SNc, VTA, IP, dorsolateral PAG, SLN (B9), DR, and MR.
Finally, other (mainly retrograde) reports have documented PL projections to VTA (Sesack and Pickel, 1992; Au-Young et al., 1999; Carr and Sesack, 2000), PCO (Canteras and Goto, 1999), DR (Peyron et al., 1998; Hajos et al., 1998; Varga et al., 2001), MR (Behzadi et al., 1990), and PAG (Beitz, 1982, Mantyh, 1982, Hardy, 1986; Neafsey et al., 1986b; Terreberry and Neafsey, 1987; Shipley et al., 1991).

\section{Overview of IL and PL projections and functional considerations}

\section{IL: visceromotor circuitry}

It is well recognized that IL modulates visceral/autonomic activity. A number of early reports (Smith, 1945; Wall and Davis, 1951; Delgado, 1961) as well as recent ones (Terreberry and Neafsey, 1983; Burns and Wyss, 1985; Hurley-Gius and Neafsey, 1986; Verberne et al., 1987; Hardy and Holmes, 1988, Neafsey, 1990; Frysztak and Neafsey, 1991, 1994) have shown that IL significantly affects various visceral functions including heart rate, blood pressure, respiration, and gastrointestinal activity. It is equally well demonstrated (Cechetto and Saper, 1990; Neafsey, 1990; Hurley et al., 1991; Takagishi and Chiba, 1991; Buchanan and Powell, 1993; Verberne and Owens, 1998) that IL projects to forebrain and brainstem sites controlling autonomic/visceromotor activity (see Fig. 12A).

Further, it has been shown that most of the major forebrain targets of IL fibers project to, and influence, autonomic nuclei of the brainstem (Saper et al., 1976, 1979; Hopkins and Holstege, 1978; Schwaber et al., 1982; Veening et al., 1984; Moga and Gray, 1985; Grove, 1988b; Moga et al., 1989, 1990a,b; Loewy, 1991; Rizvi et al., 1991, 1992, 1996; Allen and Cechetto, 1992; Vertes and Crane, 1996; Petrovich and Swanson, 1997; Murphy et al., 1999; Floyd et al., 2001), indicating direct as well as indirect IL actions on a network of interconnected nuclei subserving autonomic/visceral functions. IL is viewed as a "visceral motor cortex" (Hurley-Guis and Neafsey, 1986; Neafsey, 1990).

Related to the involvement of IL is visceral motor control, Milad and Quirk (2002) recently demonstrated the important findings that cells of the infralimbic cortex, but not those of the adjacent PL and medial orbital cortices, fired selectively during the extinction phase of fear conditioning, and were thought to mediate learned fear extinction. The authors proposed that the effect involves the suppressive action of IL on the central nucleus of the amygdala and a consequent dampening of autonomic/visceral centers contributing in fear responses (Milad and Quirk, 2002).

\section{PL: "limbic-cognitive" circuitry}

By contrast with IL, recent evidence suggests that $\mathrm{PL}$ serves a direct role in limbic/cognitive functions, homologous to the dorsolateral prefrontal cortex of pri- 
PROJECTIONS OF IL AND PL CORTEX

TABLE I. Density of labeling in nuclei of the brainstem and forebrain produced by PHA-L injections in the infralimbic and prelimbic cortices*

\begin{tabular}{|c|c|c|c|c|c|}
\hline \multirow[b]{2}{*}{ Structures } & \multicolumn{2}{|c|}{ Labeling } & \multirow[b]{2}{*}{ Structures } & \multicolumn{2}{|c|}{ Labeling } \\
\hline & IL & PL & & IL & PL \\
\hline Telencephalon & & & substantia innominata & +++ & + \\
\hline cortex & & & tania tecta & & \\
\hline cingulate & +++ & +++ & dorsal & ++ & ++ \\
\hline ectorhinal & + & -- & ventral & + & -- \\
\hline entorhinal & ++ & ++ & ventral pallidum & + & -- \\
\hline frontal polar & & & Diencephalon & & \\
\hline medial part & +++ & +++ & Thalamus & & \\
\hline lateral part & -- & -- & anterodorsal $\mathrm{n}$. & -- & -- \\
\hline infralimbic & +++ & +++ & anteromedial $\mathrm{n}$. & + & ++ \\
\hline insular & & & anteroventral $\mathrm{n}$. & -- & -- \\
\hline dorsal agranular & + & +++ & central lateral $n$. & -- & + \\
\hline ventral agranular & ++ & +++ & central medial $\mathrm{n}$. & ++ & ++ \\
\hline posterior agranular & + & -- & interanteromedial & ++ & +++ \\
\hline dysgranular & -- & -- & intermediodorsal n. & +++ & +++ \\
\hline granular & -- & -- & lateral geniculate $\mathrm{n}$. & -- & -- \\
\hline lateral agranular (motor) & -- & -- & lateral habenula & + & + \\
\hline medial agranular (motor) & + & + & laterodorsal n. & + & + \\
\hline occipital & -- & -- & lateroposterior $\mathrm{n}$. & + & + \\
\hline orbital & & & medial geniculate $\mathrm{n}$. & -- & -- \\
\hline lateral part & + & + & medial habenula & -- & -- \\
\hline medial part & +++ & +++ & mediodorsal n. & & \\
\hline ventral part & ++ & + & medial division & +++ & +++ \\
\hline ventrolateral part & + & + & central division & ++ & ++ \\
\hline perirhinal & + & ++ & lateral division & + & +++ \\
\hline piriform & & & paracentral n. & -- & -- \\
\hline anterior part & -- & + & parafascicular $\mathrm{n}$. & + & + \\
\hline posterior part & ++ & -- & paratential $\mathrm{n}$. & +++ & +++ \\
\hline prelimbic & +++ & +++ & paraventricular $\mathrm{n}$. & & \\
\hline retrosplenial & + & + & anterior part & +++ & +++ \\
\hline somatosensory I & -- & -- & posterior part & +++ & +++ \\
\hline somatosensory II & -- & -- & posterior $\mathrm{n}$. & -- & -- \\
\hline temporal & -- & -- & reticular $\mathrm{n}$. & -- & -- \\
\hline accumbens $\mathrm{n}$. & & & reuniens $\mathrm{n}$. & +++ & +++ \\
\hline shell & + & +++ & rhomboid n. & ++ & + \\
\hline core & + & +++ & submedial $\mathrm{n}$. & -- & -- \\
\hline amygdala & & & ventral anterior-lateral $\mathrm{n}$. & -- & -- \\
\hline anterior area & ++ & -- & ventral basal complex & -- & -- \\
\hline basolateral & + & +++ & Hypothalamus & & \\
\hline basomedial & +++ & + & anterior $\mathrm{n}$. & ++ & -- \\
\hline central & & & dorsal hypothalamic area & ++ & + \\
\hline capsular part & ++ & +++ & dorsomedial n. & +++ & + \\
\hline medial part & +++ & ++ & lateral n. & +++ & ++ \\
\hline cortical & & & mammillary bodies & + & -- \\
\hline anterior part & ++ & -- & paraventricular n. & -- & -- \\
\hline posterior part & + & -- & perifornical area & +++ & ++ \\
\hline medial & +++ & -- & posterior $\mathrm{n}$ & +++ & + \\
\hline lateral & + & + & premammillary $\mathrm{n}$. & & \\
\hline posterior & + & -- & dorsal & -- & -- \\
\hline anterior olfactory nucleus & & & ventral & + & -- \\
\hline medial part & +++ & ++ & supramammillary n. & ++ & ++ \\
\hline ventral part & +++ & +++ & ventromedial $\mathrm{n}$. & -- & \\
\hline bed $\mathrm{n}$. of stria terminalis & +++ & -- & Subthalamus & & \\
\hline caudate-putamen & ++ & ++ & fields of Forel & + & -- \\
\hline claustrum & -- & +++ & zona incerta & + & -- \\
\hline diagonal band $n$. & & & Brainstem & & \\
\hline horizontal limb & +++ & + & anterior pretectal $\mathrm{n}$. & -- & -- \\
\hline vertical limb & ++ & -- & Barrington's n. & + & + \\
\hline endopiriform $\mathrm{n}$. & +++ & -- & cuneiform $\mathrm{n}$. & -- & + \\
\hline globus pallidus & -- & -- & dorsal motor n. vagus & + & -- \\
\hline hippocampal formation & & & dorsal raphe $\mathrm{n}$. & + & +++ \\
\hline Ammon's horn & -- & -- & dorsal tegmental $\mathrm{n}$. & -- & -- \\
\hline dentate gyrus & -- & -- & interpeduncular $\mathrm{n}$. & ++ & + \\
\hline subiculum & -- & -- & laterodorsal tegmental $\mathrm{n}$. & + & + \\
\hline lateral septum & & & locus coeruleus & + & -- \\
\hline dorsal n. & ++ & -- & mesencephalic reticular formation & + & + \\
\hline intermediate $\mathrm{n}$. & + & -- & n. ambiguus & -- & -- \\
\hline ventral $\mathrm{n}$. & +++ & + & $\mathrm{n}$. incertus & + & ++ \\
\hline lateral preoptic area & +++ & + & $\mathrm{n}$. gigantocellularis & -- & + \\
\hline magnocellular preoptic $\mathrm{n}$. & + & + & n. pons & -- & -- \\
\hline medial preoptic area & +++ & + & n. pontis caudalis & -- & -- \\
\hline median preoptic $n$. & ++ & -- & n. pontis oralis & -- & -- \\
\hline medial septal n. & + & -- & n. posterior commissure & & \\
\hline olfactory tubercle & ++ & +++ & n. solitary tract & + & -- \\
\hline septofimbrial $\mathrm{n}$. & -- & -- & parabrachial n. & & \\
\hline septohippocampal n. & ++ & -- & medial part & ++ & -- \\
\hline
\end{tabular}


TABLE I (CONTINUED).

\begin{tabular}{lcc}
\hline & \multicolumn{2}{c}{ Labeling } \\
\cline { 2 - 3 } Structures & IL & PL \\
\hline lateral part & ++ & -- \\
pedunculopontine tegmental n. & + & + \\
periaquaductal gray, midbrain & +++ & +++ \\
periaquaductal gray, pons & + & +++ \\
peripeduncular n. & -- & + \\
reticular tegmental n. pons & -- & -- \\
retrorubral area & -- & +- \\
rostro-ventrolateral medulla & -- & +++ \\
$\quad$ pars compacta & + & + \\
pars reticulata & -- & ++ \\
surpalemniscal n. (B9) & -- & -- \\
superior colliculus & -- & ++ \\
ventral tegmental area & ++ & -- \\
ventral tegmental n. & -- & + \\
\hline
\end{tabular}

$*+$, light labeling; ++ , moderate labeling, +++ , dense labeling; -- , absence of labeling; n, nucleus; PHA-L, Phaseolus vulgaris-leucoagglutinin; for other abbreviations, see list.

mates (Kolb, 1984; Barbas, 2000; Ongur and Price, 2000). The dorsolateral PFC of primates serves a wellrecognized role in higher order processes, including decision-making, goal-directed behavior, and working memory (WM) (Goldman-Rakic, 1987, 1994; Fuster, 1989; Petrides, 1995, 1998). The function most commonly associated with the prefrontal cortex, and the one most extensively examined, is working memory; that is, the temporary storage and utilization of information over short delays (Goldman-Rakic, 1987, 1995).

An accumulating body of evidence indicates that the prefrontal cortex of rats is similarly involved in tasks requiring the maintenance of information over time including delayed alternation (Larsen and Divac, 1978; Silva et al., 1986; van Haaren et al., 1988; Brito and Brito, 1990; Bubser and Schmidt, 1990; Kesner et al., 1996; Delatour and Gisquet-Verrier, 1996, 1999) and delayed matching and nonmatching to sample tasks (Kolb et al., 1994; Granon et al., 1994; Broersen et al., 1995; Seamans et al., 1995; Harrison and Mair, 1996; Shaw and Aggleton, 1993; Young et al., 1996; Porter and Mair, 1997). Evidence further suggests that PL is the critical $\mathrm{mPFC}$ region involved in delayed responding; that is, lesions restricted to ventral mPFC (or PL) have been shown to produce the same disruptive effects on delayed response tasks as lesions of the entire medial wall of the mPFC (Brito and Brito, 1990; Seamans et al., 1995; Delatour and Gisquet-Verrier, 1996, 1999, 2000; Floresco et al., 1997; Ragozzino et al., 1998). For instance, Phillips and co-workers (Seamans et al., 1995) initially demonstrated that bilateral inactivation of PL, but not of the dorsally adjacent anterior cingulate cortex, produced severe deficits in the delayed version of an eight arm maze task, and subsequently showed that these same deficits were produced by disconnecting the hippocampus from PL (Floresco et al., 1997).

As with IL projections and visceromotor activity, PL projections support its involvement in cognitive functions. As shown (Fig. 12B), PL distributes to a rela- tively restricted number of sites and largely those known to affect cognition-or limbic influences on cognition. These include the agranular insular cortex, the claustrum, ACC (and extended ventral striatum), basolateral amygdala, the paraventricular, RE and MD of thalamus, VTA/SNc, and raphe nuclei of the midbrain (SLN, DR, and MR).

\section{PL-striatal-thalamocortical circuitry}

Similar to sensorimotor regions of cortex (Alexander et al., 1986, 1990; Gerfen, 1992, Gerfen and Wilson, 1996; Strick et al., 1994), the prefrontal cortex forms reentrant "loops" with the basal ganglia (BG) and thalamus; that is, parallel, functionally segregated, cortical-BG-thalamocortical circuits (Groenewegen et al., 1990, 1999).

In an early report in cats, Room et al. ( 1985) described pronounced projections from PL to the ACC, and further noted that the PL-ACC projection was the first leg of a cortical loop from PL; that is, according to them, a loop "from the prelimbic area via the ventral striatum, ventral pallidum, and the mediodorsal nucleus back to the prelimbic area." As discussed below, several subsequent studies have provided additional details on this system of connections that has been referred to as the "PL circuit" (Groenewegen et al., 1990).

The ACC is the major point of convergence of inputs from various structures comprising the "PL circuit"; that is, in addition to $\mathrm{PL}, \mathrm{ACC}$ receives afferents from the insular cortex, basal nucleus of amygdala, VTA, midline thalamus, ventral pallidum, and hippocampus (Groenewegen et al., 1990). The output of ACC is predominantly directed to the ventral pallidum (VP) and SNr (Groenewegen and Russchen, 1984; Zahm and Heimer, 1990, Heimer et al., 1991; Deniau et al., 1994; Zahm et al., 1996; Maurice et al., 1997; O’Donnell et al., 1997; Usuda et al., 1998; Dallvechia-Adams et al., 2001) which, in turn, project to parts of the medial/midline thalamus (mainly MD) that give rise to projections to PL, thus completing the PL-ventral striatopallidal-thalamocortical circuit (Haber et al., 1985; Groenewegen, 1988; Zahm, 1989; Ray and Price, 1992; Ray et al., 1992; Groenewegen et al., 1993, 1999; Miyamoto and Jinnai, 1994; Kuroda et al., 1995; Maurice et al., 1997; O’Donnell et al., 1997).

Two parallel (but segregated) PL-ventral BG-thalamic circuits have recently been identified: one originating from the ventral PL targeting the shell of ACC, and the other from the dorsal PL feeding the core of ACC (O'Donnell et al., 1997; Groenewegen et al., 1999). The ventral PL circuit, then, involves: ventral PL > ACC shell $>$ VPm $>$ medial subdivision of $\mathrm{MD}$ $(\mathrm{MDm})>\mathrm{PL}$; and the dorsal PL circuit involves: dorsal $\mathrm{PL}>\mathrm{ACC}$ core $>\mathrm{VPl}$ and/or dorsomedial $\mathrm{SNr}>$ central nucleus of $\mathrm{MD} /$ ventromedial nucleus of thala- 

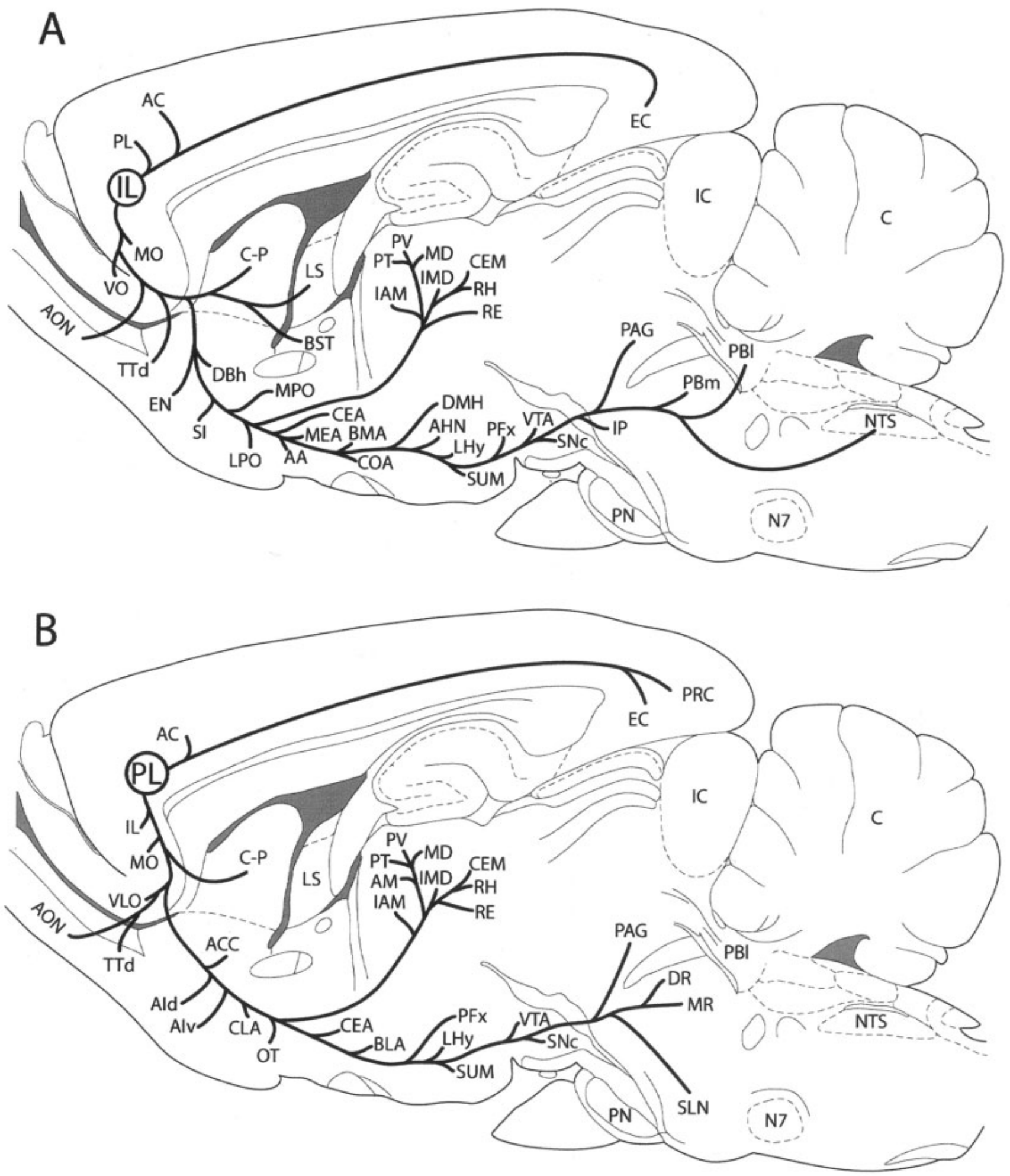

Fig. 12. Schematic sagittal sections summarizing the main projection sites of the infralimbic $(\mathbf{A})$ and prelimbic (B) cortices. Note that IL projections are much more widespread than PL projections, particularly to the basal forebrain, amygdala, and hypothalamus. Sections are modified from the rat atlas of Paxinos and Watson (1998). For illustrative purposes, several sagittal planes are collapsed onto single sagittal sections. For abbreviations, see list. 
mus > PL (O'Donnell et al., 1997; Groenewegen et al., 1999). As described (see Results), we carefully examined PL projections to the ACC but were not able to confirm selective dorsal PL projections to the core of ACC and ventral PL projections to the shell of ACC. By contrast, we observed considerable overlap in dorsal and ventral PL projections to the core and shell of ACC with only a slight tendency of dorsal PL to distribute more heavily to the core and the ventral PL more strongly to the shell. This difference in degree may not, however, negate the fact that there are segregated PL circuits-to the striatum and to other parts of the brain.

Finally, a direct role for the "PL circuit" in cognition gains support from recent demonstrations that manipulations of nuclei of the circuit (like those of PL itself) affect delay response tasks-or working memory (WM). For instance, lesions/disruption of ACC (Floresco et al., 1999), VP (Kalivas et al., 2001), and MD (Harrison and Mair, 1996; Floresco et al., 1999; Romanides et al., 1999; Kalivas et al., 2001) have been shown to alter tasks requiring working memory, but not those without a WM component.

\section{Other "limbic" structures connecting with the PL circuit}

Groenewegen et al. (1990) initially reported that the PL circuit has significant ties with other parts of the limbic system, most notably, the paraventricular nucleus of thalamus (PV) and the basolateral nucleus of amygdala (BLA). This has been substantiated by the demonstration that: 1) PV and BLA reciprocally connect with PL (Krettek and Price, 1977; Macchi et al., 1978; Beckstead, 1979; Room et al., 1985; McDonald, 1987, 1991a; Cassell et al., 1989; Sesack et al., 1989; Kita and Kitai, 1990; Berendse and Groenewegen, 1991; Shinonaga et al., 1994; Moga et al., 1995; Bacon et al., 1996; McDonald et al., 1996; Vertes, 2002); 2) PV and BLA distribute heavily to ACC (Groenewegen et al., 1980; Russchen and Price, 1984; Phillipson and Griffiths, 1985; Berendse and Groenewegen, 1990; McDonald, 1991b; Brog et al., 1993; Shinonaga et al., 1994; Moga et al., 1995; Wright and Groenewegen, 1995; Wright et al., 1996; Mulder et al., 1998); and 3) BLA afferents to thalamus selectively target midline nuclei of the thalamus (Krettek and Price, 1974, 1977; McDonald, 1987; Kuroda and Price, 1991; Ray and Price, 1992).

We confirmed pronounced PL projections to PV and BLA, and further showed that PL distributes strongly to several other structures that, in light of the notion of a "PL circuit," might be considered part of an extended PL circuitry. They primarily include the agranular insular cortex, the claustrum, the nucleus reuniens of thalamus, SNc/VTA, and raphe nuclei (MR, DR, SLN) of the brainstem (Fig. 12B).

\section{Integration of IL and PL circuitry}

As described, IL and PL project very differently throughout the brain (Table I, Fig. 12). IL mainly distributes to autonomic/visceral-related sites, supporting its role in visceromotor activity, whereas PL primarily projects to limbic sites that reportedly affect cognition.

It is obviously the case, however, that the complex goal-directed behaviors entail an integration of visceral and cognitive elements. It seems likely that this integration may largely occur at the level of the mPFC, involving interactions between IL and PL. As described, IL and PL strongly interconnect. In the rat, then, the IL/PL complex may exert significant control over emotional-cognitive aspects of behavior.

In summary, the mPFC of rats appears functionally homologous to a fairly widespread region of the prefrontal/frontal cortex of primates subserving motor, emotional, and cognitive elements of behavior; that is, the dorsal mPFC appears homologous to supplementary/premotor area, PL to dorsolateral PFC, and IL to the orbitomedial cortex of primates.

\section{ACKNOWLEDGMENT}

We thank Nedialka Todorova for superb technical assistance in all phases of this study.

\section{REFERENCES}

Alexander GE, Delong MR, Strick PL. 1986. Parallel organization of functionally segregated circuits linking basal ganglia and cortex. Annu Rev Neurosci 9:357-381.

Alexander GE, Crutcher MD, Delong MR. 1990. Basal gangliathalamocortical circuits: parallel substrates for motor, oculomotor, "prefrontal" and "limbic" functions. Prog Brain Res 85:119-146.

Allen GV, Cechetto DF. 1992. Functional and anatomical organization of cardiovascular pressor and depressor sites in the lateral hypothalamic area. I. Descending projections. J Comp Neurol 315:313332 .

Au-Young SMW, Shen H, Yang CR. 1999. Medial prefrontal cortical output neurons to the ventral tegmental area (VTA) and their responses to burst-patterned stimulation of the VTA: neuroanatomical and in vivo electrophysiological analyses. Synapse 34:245255.

Bacon SJ, Headlam AJN, Gabbott PLA, Smith AD. 1996. Amygdala input to medial prefrontal cortex (mPFC) in the rat: a light and electron microscope study. Brain Res 720:211-219.

Barbas H. 1995. Anatomic basis of cognitive-emotional interactions in the primate prefrontal cortex. Neurosci Biobehav Rev 19:499-510.

Barbas H. 2000. Connections underlying the synthesis of cognition, memory, and emotion in primate prefrontal cortices. Brain Res Bull 52:319-330.

Beckstead RM. 1979. Autoradiographic examination of corticocortical and subcortical projections of the mediodorsal-projection (prefrontal) cortex in the rat. J Comp Neurol 184:43-62.

Behzadi G, Kalen P, Parvopassu F, Wiklund L. 1990. Afferents to the median raphe nucleus of the rat: retrograde cholera-toxin and wheat-germ conjugated horseradish-peroxidase tracing, and selective D-[H-3]aspartate labeling of possible excitatory amino-acid inputs. Neuroscience 37:77-100.

Beitz A. 1982. The organization of afferent projections to the midbrain periaqueductal gray of the rat. Neuroscience 7:133-159.

Berendse HW, Groenewegen HJ. 1990. Organization of the thalamostriatal projections in the rat, with special emphasis on the ventral striatum. J Comp Neurol 299:187-228.

Berendse HW, Groenewegen HJ. 1991. Restricted cortical termination fields of the midline and intralaminar thalamic nuclei in the rat. Neuroscience 42:73-102.

Berendse HW, GalisdegraafY, Groenewegen HJ. 1992. Topographical organization and relationship with ventral striatal compartments 
of prefrontal corticostriatal projections in the rat. J Comp Neurol 316:314-347.

Brito GNO, Brito LSO. 1990. Septohippocampal system and the prelimbic sector of frontal cortex: a neuropsychological battery analysis in the rat. Behav Brain Res 36:127-146.

Broersen LM, Heinsbroek RPW, Debruin JPC, Uylings HBM, Olivier B. 1995. The role of the medial prefrontal cortex of rats in shortterm memory functioning: further support for involvement of cholinergic, rather than dopaminergic mechanisms. Brain Res 674: 221-229.

Brog JS, Salyapongse A, Deutch AY, Zahm DS. 1993. The patterns of afferent innervation of the core and shell in the accumbens part of the rat ventral striatum: immunohistochemical detection of retrogradely transported Fluoro-Gold. J Comp Neurol 338:255-278.

Bubser M, Schmidt WJ. 1990. 6-Hydroxydopamine lesion of the rat prefrontal cortex increases locomotor activity, impairs acquisition of delayed alternation tasks, but does not affect uninterrupted tasks in the radial maze. Behav Brain Res 37:157-168.

Buchanan SL, Powell DA. 1993. Cingulothalamic and prefrontal control of autonomic function. In: Vogt BA, Gabriel M., editors. Neurobiology of cingulate cortex and limbic thalamus. Cambridge, MA: Birkhauser. p 381-414.

Buchanan SL, Thompson RH, Maxwell BL, Powell DA. 1994. Efferent connections of the medial prefrontal cortex in the rabbit. Exp Brain Res 100:469-483.

Burns SM, Wyss JM. 1985. The involvement of the anterior cingulate cortex in blood pressure control. Brain Res 340:71-77.

Canteras NS, Goto M. 1999. Connections of the precommissural nucleus. J Comp Neurol 408:23-45.

Carnes KM, Fuller TA, Price JL. 1990. Sources of presumptive glutamatergic aspartatergic afferents to the magnocellular basal forebrain in the rat. J Comp Neurol 302:824-852.

Carr DB, Sesack SR. 2000. Projections from the rat prefrontal cortex to the ventral tegmental area: target specificity in the synaptic associations with mesoaccumbens and mesocortical neurons. J Neurosci 20:3864-3873.

Cassell MD, Chittick CA, Siegel MA, Wright DJ. 1989. Collateralization of the amygdaloid projections of the rat prelimbic and infralimbic cortices. J Comp Neurol 279:235-248.

Cechetto DF, Saper CB. 1990. Role of the cerebral cortex in autonomic function. In: Loewy $\mathrm{AD}$, Spyer KM, editors. Central regulation of autonomic functions. New York: Oxford University Press. p 208223

Chen S, Su HS. 1990. Afferent connections of the thalamic paraventricular and parataenial nuclei in the rat: a retrograde tracing study with iontophoretic application of Fluoro-Gold. Brain Res 522: $1-6$.

Chiba T, Kayahara T, Nakanoh K. 2001. Efferent projections of infralimbic and prelimbic areas of the medial prefrontal cortex in the Japanese monkey, Macaca fuscata. Brain Res 888:83-101.

Cornwall J, Phillipson OT. 1988. Afferent projections to the dorsal thalamus of the rat as shown by retrograde lectin transport. I. The mediodorsal nucleus. Neuroscience 24:1035-1049.

Dallvechia-Adams S, Smith Y, Kuhar MJ. 2001. CART peptide-immunoreactive projection from the nucleus accumbens targets substantia nigra pars reticulata neurons in the rat. J Comp Neurol 434:29-39.

Delatour B, Gisquet-Verrier P. 1996. Prelimbic cortex specific lesions disrupt delayed-variable response tasks in the rat. Behav Neurosci 110:1282-1298.

Delatour B, Gisquet-Verrier P. 1999. Lesions of the prelimbic-infralimbic cortices in rats do not disrupt response selection processes but induce delay-dependent deficits: evidence for a role in working memory? Behav Neurosci 113:941-955.

Delatour B, Gisquet-Verrier P. 2000. Functional role of rat prelimbicinfralimbic cortices in spatial memory: evidence for their involvement in attention and behavioural flexibility. Behav Brain Res 109:113-128.

Delgado JM. 1961. Circulatory effects of cortical stimulation. Physiol Rev 40:146-171.

Deniau JM, Menetrey A, Thierry AM. 1994. Indirect nucleus accumbens input to the prefrontal cortex via the substantia nigra pars reticulata: a combined anatomical and electrophysiological study in the rat. Neuroscience 61:533-545.

Ding DCD, Gabbott PLA, Totterdell S. 2001. Differences in the laminar origin of projections from the medial prefrontal cortex to the nucleus accumbens shell and core regions in the rat. Brain Res 917:81-89.

Donoghue JP, Wise SP. 1982. The motor cortex of the rat: cytoarchitecture and microstimulation mapping. J Comp Neurol 212:76-88.
Fisk GD, Wyss JM. 1999. Associational projections of the anterior midline cortex in the rat: intracingulate and retrosplenial connections. Brain Res 825:1-13.

Floresco SB, Seamans JK, Phillips AG. 1997. Selective roles for hippocampal, prefrontal cortical, and ventral striatal circuits in radialarm maze tasks with or without a delay. J Neurosci 17:1880-1890.

Floresco SB, Braaksma DN, Phillips AG. 1999. Thalamic-corticalstriatal circuitry subserves working memory during delayed responding on a radial arm maze. J Neurosci 19:11061-11071.

Floyd NS, Price JL, Ferry AT, Keay KA, Bandler R. 2000. Orbitomedial prefrontal cortical projections to distinct longitudinal columns of the periaqueductal gray in the rat. J Comp Neurol 422:556-578.

Floyd NS, Price JL, Ferry AT, Keay KA, Bandler R. 2001. Orbitomedial prefrontal cortical projections to hypothalamus in the rat. J Comp Neurol 432:307-328.

French SJ, Totterdell S. 2002. Hippocampal and prefrontal cortical inputs monosynaptically converge with individual projection neurons of the nucleus accumbens. J Comp Neurol 446:151-165.

Frysztak RJ, Neafsey EJ. 1991. The effect of medial frontal cortex lesions on respiration, "freezing," and ultrasonic vocalizations during conditioned emotional responses in rats. Cereb Cortex 1:418425 .

Frysztak RJ, Neafsey EJ. 1994. The effect of medial frontal cortex lesions on cardiovascular conditioned emotional responses in the rat. Brain Res 643:181-193.

Fuster JM. 1989. The prefrontal cortex. Anatomy, physiology and neuropsychology of the frontal lobe, 2nd ed. New York: Raven Press

Gerfen CR. 1992. The neostriatal mosaic: multiple levels of compartmental organization in the basal ganglia. Annu Rev Neurosci 15: $285-320$.

Gerfen CR, Wilson CJ. 1996. The basal ganglia. In: Swanson LW, Bjorklund A, Hokfelt T, editors. Handbook of chemical neuroanatomy: integrated systems of the CNS. Part III, Vol. 12. Amsterdam: Elsevier. p 371-468.

Gioanni Y, Lamarche M. 1985. A reappraisal of rat motor cortex organization by intracortical microstimulation. Brain Res 344:49 61 .

Goldman-Rakic PS. 1987. Circuitry of primate prefrontal cortex and regulation of behavior by representational memory. In: Mountcastle VB, Plum F, Geiger SR, editors. Handbook of physiology: 1. The nervous system, vol. V. Higher functions of the brain. Bethesda, MD: American Physiological Society. p 373-417.

Goldman-Rakic PS. 1994. The issue of memory in the study of prefrontal function. In: Thierry AM, Glowinsky J, Goldman-Rakic PS Christen Y, editors. Motor and cognitive functions of the prefrontal cortex. Berlin: Springer. p 112-123.

Goldman-Rakic PS. 1995. Cellular basis of working memory. Neuron 14:477-485.

Gorelova N, Yang CR. 1997. The course of neural projection from the prefrontal cortex to the nucleus accumbens in the rat. Neuroscience 76:689-706.

Granon S, Vidal C, Thinus-Blanc C, Changeux JP, Poucet B. 1994. Working memory, response selection, and effortful processing in rats with medial prefrontal lesions. Behav Neurosci 108:883-891.

Groenewegen HJ. 1988. Organization of the afferent connections of the mediodorsal thalamic nucleus in the rat, related to the mediodorsal prefrontal topography. Neuroscience 24:379-431.

Groenewegen HJ, Russchen FT. 1984. Organization of the efferent projections of the nucleus accumbens to pallidal, hypothalamic, and mesencephalic structures: a tracing and immunohistochemical study in the cat. J Comp Neurol 223:347-367.

Groenewegen HJ, Uylings HBM. 2000. The prefrontal cortex and the integration of sensory, limbic and autonomic information. Prog Brain Res 126:3-28.

Groenewegen HJ, Becker NEHM, Lohman AHM. 1980. Subcortical afferents of the nucleus accumbens septi in the cat, studied with retrograde axonal transport of horseradish peroxidase and bisbenzimid. Neuroscience 5:1903-1916.

Groenewegen HJ, Room P, Witter MP, Lohman AHM. 1982. Cortical afferents of the nucleus accumbens in the cat, studied with anterograde and retrograde transport techniques. Neuroscience 7:977996.

Groenewegen HJ, Berendse HW, Wolters JG, Lohman AHM. 1990 The anatomical relationship of the prefrontal cortex with the striatopallidal system, the thalamus and the amygdala: evidence for a parallel organization. Prog Brain Res 85:95-118.

Groenewegen HJ, Berendse HW, Haber SN. 1993. Organization of the output of the ventral striatopallidal system in the rat: ventral pallidal efferents. Neuroscience 57:113-142.

Groenewegen HJ, Galis-de Graaf Y, Smeets WJAJ. 1999. Integration and segregation of limbic cortico-striatal loops at the thalamic level: 
an experimental tracing study in rats. J Chem Neuroanat 16:167185.

Grove EA. 1988a. Efferent connections of the substantia innominata in the rat. J Comp Neurol 277:347-364.

Grove EA. 1988b. Neural associations of the substantia innominata in the rat: afferent connections. J Comp Neurol 277:315-346.

Guandalini P. 1998. The corticocortical projections of the physiologically defined eye field in the rat medial frontal cortex. Brain Res Bull 47:377-385.

Haber SN, Groenewegen HJ, Grove EA, Nauta WJH. 1985. Efferent connections of the ventral pallidum: evidence of a dual striato pallidofugal pathway. J Comp Neurol 235:322-335.

Hajos M, Richards CD, Szekely AD, Sharp T. 1998. An electrophysiological and neuroanatomical study of the medial prefrontal cortical projection to the midbrain raphe nuclei in the rat. Neuroscience 87:95-108.

Hall RD, Lindholm EP. 1974. Organization of motor and somatosensory neocortex in albino-rat. Brain Res 66:23-38.

Hardy SGP. 1986. Projections to the midbrain from the medial versus lateral prefrontal cortices of the rat. Neurosci Lett 63:159-164.

Hardy SGP, Holmes DE. 1988. Prefrontal stimulus-produced hypotension in rat. Exp Brain Res 73:249-255.

Hardy SGP, Leichnetz GR. 1981. Frontal cortical projections to the periaqueductal gray in the rat: a retrograde and orthograde horseradish peroxidase study. Neurosci Lett 23:13-17.

Harrison LM, Mair RG. 1996. A comparison of the effects of frontal cortical and thalamic lesions on measures of spatial learning and memory in the rat. Behav Brain Res 75:195-206.

Heimer L, Zahm DS, Churchill L, Kalivas PW, Wohltmann C. 1991. Specificity in the projection patterns of accumbal core and shell in the rat. Neuroscience 41:89-125.

Herkenham M. 1978. Connections of nucleus reuniens thalami: evidence for a direct thalamo-hippocampal pathway in rat. J Comp Neurol 177:589-609.

Hopkins DA, Holstege G. 1978. Amygdaloid projections to mesencephalon, pons and medulla oblongata in cat. Exp Brain Res 32:529547.

Hurley-Gius KM, Neafsey EJ. 1986. The medial frontal cortex and gastric motility: microstimulation results and their possible significance for the overall pattern of organization of rat frontal and parietal cortex. Brain Res 365:241-248.

Hurley KM, Herbert H, Moga MM, Saper CB. 1991. Efferent projections of the infralimbic cortex of the rat. J Comp Neurol 308:249276.

Kalivas PW, Jackson D, Romanidies A, Wyndham L, Duffy P. 2001. Involvement of pallidothalamic circuitry in working memory. Neuroscience 104:129-136.

Kesner RP, Hunt ME, Williams JM, Long JM. 1996. Prefrontal cortex and working memory for spatial response, spatial location, and visual object information in the rat. Cereb Cortex 6:311-318.

Kita H, Kitai ST. 1990. Amygdaloid projections to the frontal cortex and the striatum in the rat. J Comp Neurol 298:40-49.

Kolb B. 1984. Functions of the frontal cortex of the rat: a comparative review. Brain Res Rev 8:65-98.

Kolb B. 1990. Animal models for human PFC-related disorders. Prog Brain Res 85:501-519.

Kolb B, Buhrmann K, McDonald R, Sutherland RJ. 1994. Dissociation of the medial prefrontal, posterior parietal, and posterior temporal cortex for spatial navigation and recognition memory in the rat. Cereb Cortex 4:664-680.

Kowianowski P, Morys J, Karwacki Z, Dziewiatkowski J, Narkiewicz O. 1998. The cortico-related zones of the rabbit claustrum: study of the claustrocortical connections based on the retrograde axonal transport of fluorescent tracers. Brain Res 784:199-209.

Krettek JE, Price JL. 1974. Direct input from amygdala to thalamus and cerebral cortex. Brain Res 67:169-174.

Krettek JE, Price JL. 1977. Projections from amygdaloid complex to cerebral cortex and thalamus in rat and cat. J Comp Neurol 172: 687-722.

Kuroda M, Price JL. 1991. Synaptic organization of projections from basal forebrain structures to the mediodorsal thalamic nucleus of the rat. J Comp Neurol 303:513-533.

Kuroda M, Murakami K, Kishi K, Price JL. 1995. Thalamocortical synapses between axons from the mediodorsal thalamic nucleus and pyramidal cells in the prelimbic cortex of the rat. J Comp Neurol 356:143-151.

Larsen JK, Divac I. 1978. Selective ablations within prefrontal cortex of rat and performance of delayed alternation. Physiol Psychol 6:15-17.

Leichnetz GR, Gonzalo-Ruiz A. 1987. Collateralization of frontal eye field (medial precentral/anterior cingulate) neurons projecting to the paraoculomotor region, superior colliculus, and medial pontine reticular formation in the rat: a fluorescent double-labeling study. Exp Brain Res 68:355-364.

Leichnetz GR, Hardy SGP, Carruth MK. 1987. Frontal projections to the region of the oculomotor complex in the rat: a retrograde and anterograde HRP study. J Comp Neurol 263:387-399.

Leonard CM. 1969. The prefrontal cortex of the rat. I. Cortical projection of the mediodorsal nucleus. II. Efferent connections. Brain Res 12:321-343.

Levesque M, Parent A. 1998. Axonal arborization of corticostriatal and corticothalamic fibers arising from prelimbic cortex in the rat. Cereb Cortex 8:602-613.

Li Y, Wolf ME. 1997. Ibotenic acid lesions of prefrontal cortex do not prevent expression of behavioral sensitization to amphetamine. Behav Brain Res 84:285-289.

Loewy AD. 1991. Forebrain nuclei involved in autonomic control. Prog Brain Res 87:253-268.

Macchi G, Bentivoglio M, Rossini P, Tempesta E. 1978. Basolateral amygdaloid projections to neocortex in cat. Neurosci Lett 9:347351 .

Majak K, Kowianski P, Morys J, Spodnik J, Karwacki Z, Wisniewski HM. 2000. The limbic zone of the rabbit and rat claustrum: a study of the claustrocingulate connections based on the retrograde axonal transport of fluorescent tracers. Anat Embryol 201:15-25.

Mantyh PW. 1982. Forebrain projections to the periaqueductral gray in the monkey, with observations in the cat and rat. J Comp Neurol 206:146-158.

Markowitsch HJ, Irle E, Bangolsen R, Flindtegebak P. 1984. Claustral efferents to the cats limbic cortex studied with retrograde and anterograde tracing techniques. Neuroscience 12:409-425.

Maurice N, Deniau JM, Menetrey A, Glowinski J, Thierry AM. 1997. Position of the ventral pallidum in the rat prefrontal cortex basal ganglia circuit. Neuroscience 80:523-534.

McDonald AJ. 1987. Organization of amygdaloid projections to the mediodorsal thalamus and prefrontal cortex: a fluorescence retrograde transport study in the rat. J Comp Neurol 262:46-58.

McDonald AJ. 1991a. Topographical organization of amygdaloid projections to the caudatoputamen, nucleus accumbens, and related striatal-like areas of the rat brain. Neuroscience 44:15-33.

McDonald AJ. 1991b. Organization of amygdaloid projections to the prefrontal cortex and associated striatum in the rat. Neuroscience 44:1-14.

McDonald AJ, Mascagni F, Guo L. 1996. Projections of the medial and lateral prefrontal cortices to the amygdala: a Phaseolus vulgaris leucoagglutinin study in the rat. Neuroscience 71:55-75.

McGeorge AJ, Faull RLM. 1989. The organization of the projection from the cerebral cortex to the striatum in the rat. Neuroscience 29:503-537.

Miyamoto Y, Jinnai K. 1994. The inhibitory input from the substantia nigra to the mediodorsal nucleus neurons projecting to the prefrontal cortex in the cat. Brain Res 649:313-318.

Moga MM, Gray TS. 1985. Evidence for corticotropin-releasing factor, neurotensin, and somatostatin in the neural pathway from the central nucleus of the amygdala to the parabrachial nucleus. J Comp Neurol 241:275-284.

Moga MM, Saper CB, Gray TS. 1989. Bed nucleus of the stria terminalis: cytoarchitecture, immunohistochemistry, and projection to the parabrachial nucleus in the rat. J Comp Neurol 283:315-332.

Moga MM, Herbert H, Hurley KM, Yasui Y, Gray TS, Saper CB. 1990a. Organization of cortical, basal forebrain, and hypothalamic afferents to the parabrachial nucleus in the rat. J Comp Neurol 295:624-661.

Moga MM, Saper CB, Gray TS. 1990b. Neuropeptide organization of the hypothalamic projection to the parabrachial nucleus in the rat. J Comp Neurol 295:662-682.

Moga MM, Weis RP, Moore RY. 1995. Efferent projections of the paraventricular thalamic nucleus in the rat. J Comp Neurol 359: 221-238.

Montaron MF, Deniau JM, Menetrey A, Glowinski J, Thierry AM. 1996. Prefrontal cortex inputs of the nucleus accumbens-nigrothalamic circuit. Neuroscience 71:371-382

Mulder AB, Gijsberti Hodenpijl MG, da Silva FHL. 1998. Electrophysiology of the hippocampal and amygdaloid projections to the nucleus accumbens of the rat: convergence, segregation, and interaction of inputs. J Neurosci 18:5095-5102.

Murphy AZ, Rizvi TA, Ennis M, Shipley MT. 1999. The organization of preoptic-medullary circuits in the male rat: evidence for interconnectivity of neural structures involved in reproductive behavior, antinociception and cardiovascular regulation. Neuroscience 91:1103-1116.

Neafsey EJ. 1990. Prefrontal cortical control of the autonomic nervous system: anatomical and physiological observations. Prog Brain Res 85:147-166. 
Neafsey EJ, Sievert C. 1982. A second forelimb motor area exists in rat frontal cortex. Brain Res 232:151-156.

Neafsey EJ, Bold EL, Haas G, Hurleygius KM, Quirk G, Sievert CF, Terreberry RR. 1986a. The organization of the rat motor cortex: a microstimulation mapping study. Brain Res Rev 11:77-96.

Neafsey EJ, Hurley-Gius KM, Arvanitis D. 1986b. The topographical organization of neurons in the rat medial frontal, insular and olfactory cortex projecting to the solitary nucleus, olfactory bulb, periaqueductal gray and superior colliculus. Brain Res 377:261-270.

Newman R, Winans SS. 1980. An experimental study of the ventral striatum of the golden hamster. I. Neuronal connections of the nucleus accumbens. J Comp Neurol 191:167-192.

O'Donnell P, Lavin A, Enquist LW, Grace AA, Card JP. 1997. Interconnected parallel circuits between rat nucleus accumbens and thalamus revealed by retrograde transynaptic transport of pseudorabies virus. J Neurosci 17:2143-2167.

Ongur D, Price JL. 2000. The organization of networks within the orbital and medial prefrontal cortex of rats, monkeys and humans. Cereb Cortex 10:206-219.

Passingham RE, Myers C, Rawlins N, Lightfoot V, Fearn S. 1988. Premotor cortex in the rat. Behav Neurosci 102:101-109.

Paxinos G, Watson C. 1998. The rat brain in stereotaxic coordinates, 4th ed. New York: Academic Press.

Petrides M. 1995. Impairments on nonspatial self-ordered and externally ordered working memory tasks after lesions of the mid-dorsal part of the lateral frontal cortex in the monkey. J Neurosci 15:359375

Petrides M. 1998. Specialized systems for the processing of mnemonic information within the primate frontal cortex. In: Roberts AC, Robbins TW, Weiskrantz L, editors. The prefrontal cortex: executive and cognitive functions. New York: Oxford University Press. p $103-116$.

Petrovich GD, Swanson LW. 1997. Projections from the lateral part of the central amygdalar nucleus to the postulated fear conditioning circuit. Brain Res 763:247-254.

Peyron C, Petit JM, Rampon C, Jouvet M, Luppi PH. 1998. Forebrain afferents to the rat dorsal raphe nucleus demonstrated by retrograde and anterograde tracing methods. Neuroscience 82:443-468.

Phillipson OT, Griffiths AC. 1985. The topographic order of inputs to nucleus accumbens in the rat. Neuroscience 16:275-296.

Pierce RC, Kalivas PW. 1997. A circuitry model of the expression of behavioral sensitization to amphetamine-like psychostimulants. Brain Res Rev 25:192-216.

Porter MC, Mair RG. 1997. The effects of frontal cortical lesions on remembering depend on the procedural demands of tasks performed in the radial arm maze. Behav Brain Res 87:115-125.

Price JL. 1995. Thalamus. In: Paxinos G, editor. The rat nervous system, 2nd ed. New York: Academic Press. p 629-648.

Ragozzino ME, Adams S, Kesner RP. 1998. Differential involvement of the dorsal anterior cingulate and prelimbic-infralimbic areas of the rodent prefrontal cortex in spatial working memory. Behav Neurosci 112:293-303.

Ray JP, Price JL. 1992. The organization of the thalamocortical connections of the mediodorsal thalamic nucleus in the rat, related to the ventral forebrain prefrontal cortex topography. J Comp Neurol 323:167-197.

Ray JP, Russchen FT, Fuller TA, Price JL. 1992. Sources of presumptive glutamatergic aspartatergic afferents to the mediodorsal nucleus of the thalamus in the rat. J Comp Neurol 320:435-456.

Reep RL, Corwin JV, Hashimoto A, Watson RT. 1984. Afferent connections of medial precentral cortex in the rat. Neurosci Lett 44: $247-252$.

Reep RL, Corwin JV, Hashimoto A, Watson RT. 1987. Efferent connections of the rostral portion of medial agranular cortex in rats. Brain Res Bull 19:203-221.

Reep RL, Goodwin GS, Corwin JV. 1990. Topographic organization in the corticocortical connections of medial agranular cortex in rats. J Comp Neurol 294:262-280.

Risold PY, Thompson RH, Swanson LW. 1997. The structural organization of connections between hypothalamus and cerebral cortex. Brain Res Rev 24:197-254.

Rizvi TA, Ennis M, Behbehani MM, Shipley MT. 1991. Connections between the central nucleus of the amygdala and the midbrain periaqueductal gray: topography and reciprocity. J Comp Neurol 303:121-131.

Rizvi TA, Ennis M, Shipley MT. 1992. Reciprocal connections between the medial preoptic area and the midbrain periaqueductal gray in rat: a WGA-HRP and PHA-L study. J Comp Neurol 315:1-15.

Rizvi TA, Murphy AZ, Ennis M, Behbehani MM, Shipley MT. 1996. Medial preoptic area afferents to periaqueductal gray medullooutput neurons: a combined Fos and tract tracing study. J Neurosci $16: 333-344$.
Romanides AJ, Duffy P, Kalivas PW. 1999. Glutamatergic and dopaminergic afferents to the prefrontal cortex regulate spatial working memory in rats. Neuroscience 92:97-106.

Room P, Russchen FT, Groenewegen HJ, Lohman AHM. 1985. Efferent connections of the prelimbic (area 32) and the infralimbic (area 25) cortices: an anterograde tracing study in the cat. J Comp Neurol 242:40-55.

Ross CA, Ruggiero DA, Reis DJ. 1981. Afferent projections to cardiovascular portions of the nucleus of the tractus solitarius in the rat. Brain Res 223:402-408.

Russchen FT, Price JL. 1984. Amygdalostriatal projections in the rat. Topographical organization and fiber morphology shown using the lectin PHA-L as an anterograde tracer. Neurosci Lett 47:15-22.

Russchen FT, Amaral DG, Price JL. 1985. The afferent connections of the substantia innominata in the monkey, Macaca fascicularis. J Comp Neurol 242:1-27.

Sanderson KJ, Welker W, Shambes GM. 1984. Reevaluation of motor cortex and of sensorimotor overlap in cerebral cortex of albino rats. Brain Res 292:251-260.

Saper CB. 1982a. Reciprocal parabrachial-cortical connections in the rat. Brain Res 242:33-40.

Saper CB. 1982b. Convergence of autonomic and limbic connections in the insular cortex of the rat. J Comp Neurol 210:163-173.

Saper CB, Swanson LW, Cowan WM. 1976. Direct hypothalamoautonomic connections. Brain Res 117:305-312.

Saper CB, Swanson LW, Cowan WM. 1979. Autoradiographic study of the efferent connections of the lateral hypothalamic area in the rat. J Comp Neurol 183:689-706.

Schwaber JS, Kapp BS, Higgins GA, Rapp PR. 1982. Amygdaloid and basal forebrain direct connections with the nucleus of the solitary tract and the dorsal motor nucleus. J Neurosci 2:1424-1438.

Seamans JK, Floresco SB, Phillips AG. 1995. Functional differences between the prelimbic and anterior cingulate regions of the rat prefrontal cortex. Behav Neurosci 109:1063-1073.

Seki M, Zyo K. 1984. Anterior thalamic afferents from the mamillary body and the limbic cortex in the rat. J Comp Neurol 229:242-256.

Sesack SR, Pickel VM. 1992. Prefrontal cortical efferents in the rat synapse on unlabeled neuronal targets of catecholamine terminals in the nucleus accumbens septi and on dopamine neurons in the ventral tegmental area. J Comp Neurol 320:145-160.

Sesack SR, Deutch AY, Roth RH, Bunney BS. 1989. Topographical organization of the efferent projections of the medial prefrontal cortex in the rat: an anterograde tract-tracing study with Phaseolus vulgaris leucoagglutinin. J Comp Neurol 290:213-242.

Shaw C, Aggleton JP. 1993. The effects of fornix and medial prefrontal lesions on delayed non-matching-to-sample by rats. Behav Brain Res 54:91-102.

Sherk H. 1988. The claustrum and the cerebral cortex. In: Jones EG Peters A, editors. Cerebral cortex, vol. 5. Sensory-motor areas and aspects of cortical connectivity. New York: Plenum Press. p 467499 .

Shi CJ, Cassell MD. 1998. Cortical, thalamic, and amygdaloid connections of the anterior and posterior insular cortices. J Comp Neurol 399:440-468.

Shinonaga Y, Takada M, Mizuno N. 1994. Topographic organization of collateral projections from the basolateral amygdaloid nucleus to both the prefrontal cortex and nucleus accumbens in the rat. Neuroscience 58:389-397.

Shipley MT, Ennis M, Rizvi TA, Behbehani MM. 1991. Topographical specificity of forebrain inputs to the midbrain periaqueductal gray: evidence for discrete longitudinally organized input columns. In: Depaulis A, Bandler R, editors. The midbrain periaqueductal gray matter. New York: Plenum Press. p 417-448.

Silva MG, Boyle MA, Finger S, Numan B, Bouzrara AA, Almli CR. 1986. Behavioral effects of large and small lesions of the rat medial frontal cortex. Exp Brain Res 65:176-181.

Sinnamon HM, Galer BS. 1984. Head movements elicited by electrical stimulation of the anteromedial cortex of the rat. Physiol Behav $33: 185-190$

Sloniewski P, Usunoff KG, Pilgrim C. 1986. Retrograde transport of fluorescent tracers reveals extensive ipsilateral and contralateral claustrocortical connections in the rat. J Comp Neurol 246:467477.

Smith WK. 1945. The functional significance of the rostral cingular cortex as revealed by its responses to electrical excitation. J Neurophysiol 8:241-255.

Strick PL, Dum PD, Picard N. 1994. Macro-organization of the circuits connecting the basal ganglia with the cortical motor areas. In: Houk JC, Davis JL, Beiser DG, editors. Models of information processing in the basal ganglia. Cambridge, MA: MIT Press. $p$ $117-130$. 
Stuesse SL, Newman DB. 1990. Projections from the medial agranular cortex to brain stem visuomotor centers in rats. Exp Brain Res 80:532-544.

Swanson LW. 1998. Brain maps: structure of the rat brain. New York: Elsevier.

Takagishi M, Chiba T. 1991. Efferent projections of the infralimbic (area 25) region of the medial prefrontal cortex in the rat: an anterograde tracer PHA-L study. Brain Res 566:26-39.

Terreberry RR, Neafsey EJ. 1983. Rat medial frontal cortex: a visceral motor region with a direct projection to the solitary nucleus. Brain Res 278:245-249.

Terreberry RR, Neafsey EJ. 1987. The rat medial frontal cortex projects directly to autonomic regions of the brain stem. Brain Res Bull 19:639-649.

Usuda I, Tanaka K, Chiba T. 1998. Efferent projections of the nucleus accumbens in the rat with special reference to subdivision of the nucleus: biotinylated dextran amine study. Brain Res 797:73-93.

van Bockstaele EJ, Pieribone VA, Aston-Jones G. 1989. Diverse afferents converge on the nucleus paragigantocellularis in the rat ventrolateral medulla: retrograde and anterograde tracing studies. J Comp Neurol 290:561-584.

van der Kooy D, Koda LY, McGinty JF, Bloom FE. 1984. The organization of projections from the cortex, amygdala, and hypothalamus to the nucleus of the solitary tract in rat. J Comp Neurol 224:1-24.

van Haaren F, Vanzijderveld G, Vanhest A, Debruin JPC. 1988. Acquisition of conditional associations and operant delayed spatial response alternation: effects of lesions in the medial prefrontal cortex. Behav Neurosci 102:481-488.

Varga V, Szekely AD, Csillag A, Sharp T, Hajos M. 2001. Evidence for a role of GABA interneurones in the cortical modulation of midbrain 5-hydroxytryptamine neurones. Neuroscience 106:783-792.

Veening JG, Swanson LW, Sawchenko PE. 1984. The organization of projections from the central nucleus of the amygdala to brainstem sites involved in central autonomic regulation: a combined retrograde transport immunohistochemical study. Brain Res 303:337357 .

Verberne AJM, Owens NC. 1998. Cortical modulation of the cardiovascular system. Prog Neurobiol 54:149-168.

Verberne AJM, Lewis SJ, Worland PJ, Beart PM, Jarrott B, Christie MJ, Louis WJ. 1987. Medial prefrontal cortical lesions modulate baroreflex sensitivity in the rat. Brain Res 426:243-249.

Vertes RP. 2002. Analysis of projections from the medial prefrontal cortex to the thalamus in the rat, with emphasis on nucleus reuniens. J Comp Neurol 442:163-187.
Vertes RP, Crane AM. 1996. Descending projections of the posterior nucleus of the hypothalamus: Phaseolus vulgaris leucoagglutinin analysis in the rat. J Comp Neurol 374:607-631.

Vertes RP, Crane AM. 1997. Distribution, quantification, and morphological characteristics of serotonin-immunoreactive cells of the supralemniscal nucleus (B9) and pontomesencephalic reticular formation in the rat. J Comp Neurol 378:411-424.

Wall PD, Davis GD. 1951. Three cerebral cortical systems affecting autonomic function. J Neurophysiol 14:507-517.

Witter MP, Room P, Groenewegen HJ, Lohman AHM. 1988. Reciprocal connections of the insular and piriform claustrum with limbic cortex: an anatomical study in the cat. Neuroscience 24:519-539.

Wolf ME. 1998. The role of excitatory amino acids in behavioral sensitization to psychomotor stimulants. Prog Neurobiol 54:679720 .

Wolf ME, Dahlin SL, Hu XT, Xue CJ, White K. 1995. Effects of lesions of prefrontal cortex, amygdala, or fornix on behavioral sensitization to amphetamine - comparison with N-methyl-D-aspartate antagonists. Neuroscience 69:417-439.

Wright CI, Groenewegen HJ. 1995. Patterns of convergence and segregation in the medial nucleus accumbens of the rat: relationships of prefrontal cortical, midline thalamic, and basal amygdaloid afferents. J Comp Neurol 361:383-403.

Wright CI, Beijer AVJ, Groenewegen HJ. 1996. Basal amygdaloid complex afferents to the rat nucleus accumbens are compartmentally organized. J Neurosci 16:1877-1893.

Young HL, Stevens AA, Converse E, Mair RG. 1996. A comparison of temporal decay in place memory tasks in rats (Rattus norvegicus) with lesions affecting thalamus, frontal cortex, or the hippocampal system. Behav Neurosci 110:1244-1260.

Zahm DS. 1989. The ventral striatopallidal parts of the basal ganglia in the rat. II. Compartmentation of ventral pallidal efferents. Neuroscience 30:33-50.

Zahm DS, Heimer L. 1990. Two transpallidal pathways originating in the rat nucleus accumbens. J Comp Neurol 302:437-446.

Zahm DS, Williams E, Wohltmann C. 1996. Ventral striatopallidothalamic projection. IV. Relative involvements of neurochemically distinct subterritories in the ventral pallidum and adjacent parts of the rostroventral forebrain. J Comp Neurol 364:340-362.

Zhang X, Hannesson DK, Saucier DM, Wallace AE, Howland J, Corcoran ME. 2001. Susceptibility to kindling and neuronal connections of the anterior claustrum. J Neurosci 21:3674-3687. 